\title{
Fracture response of externally flawed aluminum cylindrical shells under internal gaseous detonation loading
}

\author{
Tong Wa Chao and Joseph E. Shepherd \\ Graduate Aeronautical Laboratories, California Institute of Technology, Pasadena, \\ CA 91125, U.S.A.
}

December 16, 2003 - Revised April 4, 2005

\begin{abstract}
Experiments were performed to observe the fracture behavior of thinwall and initially-flawed aluminum tubes to internal gaseous detonation loading. The load can be characterized as a propagating pressure jump with speed of $2.4 \mathrm{~km} / \mathrm{s}$ and magnitude ranging from 2 to $6 \mathrm{MPa}$, followed by an expansion wave. Flaws were machined as external axial surface notches. Cracks ran both in the upstream and downstream directions as the hoop stress opened up the notch. Different kinds of crack propagation behavior were observed for various loading amplitudes and flaw sizes. For low-amplitude loading and short flaws, cracks tend to run in a helical fashion, whereas for high-amplitude loading and long flaws, cracks tend to bifurcate in addition to running helically. Unless the cracks branched and traveled far enough to meet, resulting in a split tube, they were always arrested. Strain gages were used to monitor the hoop strains at several places on the tubes' external surface. Far from the notch, tensile vibrations were measured with frequencies matching those predicted by the steady-state Tang (1965) and Simkins (1987) models. Near the notch, compressive strains were recorded as a result of the bulging at the notch. Features in the strain signals corresponding to different fracture events are analyzed.
\end{abstract}

Keywords: tube fracture, detonation, crack branching, crack curving

\section{Introduction}

Detonation-driven tube fracture is distinguished from quasi-statically loaded tube fracture for two main reasons. First, flexural waves set up by traveling loads can cause dynamic strains that are oscillatory and have amplitudes several times higher than those predicted by static formulas. These amplitudes and frequencies are dependent on the speed of the traveling load. Second, for quasi-statically loaded tubes, the stored elastic energy caused by prestress everywhere in the tube can provide a substantially higher crack driving force than in the case of traveling loads. For a detailed comparison between the two cases, the reader is referred to Chao and Shepherd (2004).

This study is motivated by the fracture-mechanics driven design and safety criteria for pressure vessels under gaseous detonation loading. At this time, there is a lack of standard guidance in designing and testing pressure vessels and piping under explosive or detonation loading (ASME, 2000). Engineering applications include tubes that are

(C) 2005 Kluwer Academic Publishers. Printed in the Netherlands. 
deliberately loaded by detonations such as pulse detonation engines and gaseous detonation tubes for research purposes, and also tubes that may experience accident explosions, such as gas transmission pipelines, nuclear plant, and petrochemical piping. This study may also guide forensic analysis of accidental detonation-driven pipeline ruptures by identifying the key differences in fracture behavior between static and dynamic loading.

Although literature on fracture mechanics of cylindrical pressure vessels and pipelines is abundant, most of it deals with quasi-static or fatigue loading. Examples of work done on statically loaded fracture of tubes include the pioneering analysis of through-wall cracked cylindrical shells by Folias (1965), full-scale gas transmission pipeline fracture experiments by Maxey et al. (1971), Kiefner et al. (1973), Ives et al. (1974), and laboratory-scale pipe fracture experiments in conjunction with analytical and numerical efforts such as those of Emery et al. (1986) and Kobayashi et al. (1988). There are also recent computational efforts such as the one by Zhuang and O'Donoghue (2000) to simulate the fluid-structure-fracture interaction of a bursting pipe under initially static loading. The structural response of shells to shock or detonation loading was studied by researchers such as Tang (1965), Reismann (1965), de Malherbe et al. (1966), Brossard and Renard (1979), Simkins (1987), and Thomas (2002), but these were done on tubes that did not have deliberate preflaws and, thus, did not involve a fracture mechanics approach. The current study provides experimental data that connects fracture mechanics and cylindrical shell dynamics.

Our experiments have seven aspects. The first is the qualitative behavior of the crack path of a fractured tube as a function of initial flaw length. The second deals with the quantitative measurements of strain history on the rupturing tube. The third is an estimate of the fracture threshold, which is of engineering value in determining what the residual strength of a tube will be if it is flawed. The fracture threshold divides a non-dimensional parametrized test space into rupture (i.e., surface notch becoming a through-wall crack) and no rupture zones. Given a detonation wave of certain magnitude and a flaw of certain size, one can use this threshold model to estimate whether a surface flaw will break through the wall. The fourth aspect is how the appearance of the fracture surfaces changes as the cracks progress along the tube. This is important for investigations of pressure vessel or pipeline rupture accidents because the fracture surfaces can indicate how the structure is being loaded, and perhaps allow investigators to deduce the crack direction from the fragments. The fifth aspect concerns how crack branching could be related to the direction of propagation of a detonation wave. The sixth aspect studies the influence of static 
prestress on the crack curving direction. The seventh deals with the extent of the influence of the rupture event on the detonation wave.

Previous work was done at Caltech by Beltman et al. (1999) and Beltman and Shepherd (2002) to investigate the linear elastic structural response of unflawed cylindrical shells to internal shock and detonation loading. These analytical, numerical, and experimental studies demonstrated that the amplitude of the linear elastic strains is related to the speed of the shock or detonation wave. In the present study, the speed of the detonation wave is close to that given by the ChapmanJouguet (CJ) model and is determined by thermodynamics as discussed by Fickett and Davis (2000). The pressure loading produced by the detonation is traveling load with a leading edge or front traveling at the CJ velocity. The pressure rises suddenly behind the leading front to reach the CJ value and then decays approximately exponentially to a plateau value of approximately one-half the CJ pressure, see Beltman and Shepherd (2002) for details of the loading profile. The sharp rise in pressure propagating along the axis of the tube creates an impulsive radial load that excites structural oscillations. In our previous studies, we examined only the elastic aspects of these oscillations; the present work extends our studies to the nonlinear regime of structural failure due to fracture and plastic deformation.

\section{Analytical models}

There is currently no analytical model in the literature that can predict the burst pressure of an initially-flawed detonation tube. The motivation to predict the burst pressure is relevant to industrial applications and the present experiments. If a pressure vessel or pipe is flawed and is expected to withstand a detonation load, it is important to know its residual strength. In the present experiments, knowing the burst pressure or critical flaw size lets us predict which specimens will rupture and instrument them accordingly.

Two important aspects of the fracture threshold model are taken into account. The first consideration is $\Phi$, the dynamic amplification factor that determines strain amplitude as a function of the speed of the traveling load. The second consideration is the stress intensity factor of a partially-through-wall cracked specimen. A static stress intensity factor is used because there is no existing dynamic derivation for traveling loads. Therefore, the only parameter that accounts for the dynamic effect is $\Phi$, the dynamic amplification factor. Although this threshold model may be oversimplified, it can be compared to experimental data to ascertain its usefulness. 


\subsection{The Dynamic Amplification Factor due to an Internal TRAVELING LOAD}

The model presented by Tang (1965) enables the calculation of the steady-state linearly elastic strains (in the shock-fixed frame) of an unflawed thin-wall tube subjected to shock or detonation loading. The formulation includes shear deformation and rotary inertia. The model implies that there are four critical speeds associated with the structural waves excited by the traveling pressure load. The speed $v_{c 0}$ is the first critical velocity and corresponds to a resonance between the group velocity of the structural waves and the phase velocity of the detonation (see the extensive discussion in Beltman and Shepherd, 2002). Each of the critical velocities can be calculated from the vanishing of the discriminant

$$
A_{2}^{2}-4 A_{0} A_{4}=0,
$$

where

$$
\begin{aligned}
& A_{4}=\left[\left(\frac{v}{v_{d}}\right)^{2}-1\right]\left[\left(\frac{v}{v_{s}}\right)^{2}-1\right] \\
& A_{2}=\left(\frac{v}{v_{d}}\right)^{2}\left[1+\beta^{2}\left(\frac{v_{d}}{v_{s}}\right)^{2}\right]-\beta^{2}\left(1-\nu^{2}\right)\left(\frac{v_{d}}{v_{s}}\right)^{2}, \\
& A_{0}=\beta^{2}+\frac{\beta^{2} \nu^{2}}{\left[\left(\frac{v}{v_{d}}\right)^{2}-1\right]},
\end{aligned}
$$

where the shell thickness parameter is

$$
\beta=\frac{h}{\sqrt{12} R} .
$$

where $h$ and $R$ are the wall thickness and mean radius, respectively. $v$ is the speed of the traveling load, $v_{s}$ is the shear wave speed, and $v_{d}$ is the plane stress dilatational wave speed. The other critical velocities are $v_{c 1}$, equal to the modified shear wave speed

$$
v_{c 1}=\sqrt{\frac{\kappa G}{\rho}} ;
$$

the dilatational wave speed in a bar,

$$
v_{c 2}=\sqrt{\frac{E}{\rho}} ;
$$


and $v_{c 3}$, equal to the dilatational wave speed

$$
v_{c 3}=v_{d}=\sqrt{\frac{E}{\rho\left(1-\nu^{2}\right)}} .
$$

where $E$ is the Young's modulus, $G$ is the shear modulus, $\nu$ is the Poisson's ratio, $\rho$ is the density, and $\kappa$ is the shear correction factor. For a more detailed discussion on these cases, the reader is referred to Tang (1965).

A simpler model was given by Simkins (1987), whose analysis neglects rotatory inertia and shear deformation. In this model, there is a closed form for the first critical speed $v_{c 0}$, which is useful for estimating critical speeds

$$
v_{c 0}=\left[\frac{E^{2} h^{2}}{3 \rho^{2} R^{2}\left(1-\nu^{2}\right)}\right]^{\frac{1}{4}} .
$$

The dynamic amplification factor is defined as the ratio between the maximum dynamic strain and the equivalent static strain calculated from static formulas using the measured peak applied pressure

$$
\Phi=\frac{\epsilon_{\text {dynamic_max }}}{\epsilon_{\text {static }}},
$$

and is plotted as a function of the detonation or shock wave speed in Fig. 1. This factor goes from about 1 below $v_{c 0}$ to unbounded at $v_{c 0}$, and drops to about 2 between $v_{c 0}$ and $v_{c 1}$. The variation of dynamic strain as a function of the speed of the traveling load was shown experimentally and numerically in the extensive studies by Beltman and Shepherd (2002) and Beltman et al. (1999) on a detonation tube and a shock tube, respectively. Since the present experiments operate at the region far above $v_{c 0}$ but below $v_{c 1}$, the dynamic amplification factor can be approximated as 2 .

\subsection{A Simple Fracture Threshold Model for Detonation TUBES}

In linear elastic fracture mechanics, mode-I fracture initiates when the stress intensity factor $K_{I}$ reaches the fracture toughness $K_{I c}$. Since currently there is no analytical model for the dynamic stress intensity factor for a detonation tube with an external axial flaw, the well-known static relations will be used to estimate the stress intensity factor in our simplified model. To account for the dynamic strains, a dynamic amplification factor due to flexural wave excitation (see section 2.1) was incorporated in this threshold model. "Rupture" is identified with 
the notch breaking into a through-wall crack, and for simplification, it is assumed to be synonymous with $K_{I}$ reaching $K_{I c}$ at the notch front.

The static model is based on the assumption that a thin-wall tube with an external axial notch under internal pressure can be treated, neglecting curvature, as a wide plate with a surface crack under far-field tension (Figs. 2 and 3). The following results of static three-dimensional finite-element analysis of a wide plate with a surface crack by Newman and Raju (1981) will be used:

$$
K_{I}=\sigma \sqrt{\frac{\pi d}{Q}} H
$$

where

$$
\begin{gathered}
H=M_{1}+M_{2}\left(\frac{d}{h}\right)^{2}+M_{3}\left(\frac{d}{h}\right)^{4}, \\
Q=1+1.464\left(\frac{d}{a}\right)^{1.65},
\end{gathered}
$$

and

$$
\begin{gathered}
M_{1}=1.13-0.09\left(\frac{d}{a}\right), \\
M_{2}=\frac{0.89}{\left[0.2+\left(\frac{d}{a}\right)\right]}-0.54, \\
M_{3}=0.5-\frac{1.0}{\left[0.65+\left(\frac{d}{a}\right)\right]}+14\left[1.0-\left(\frac{d}{a}\right)\right]^{24} .
\end{gathered}
$$

The $K_{I}$ defined above describes the stress intensity at the deepest point of penetration for small values of $d / a$. The fracture condition is identified with

$$
K_{I}=\sigma \sqrt{\frac{\pi d}{Q}} H \geq K_{I c} .
$$

Substituting $\sigma=\sigma_{\text {dynamic_max }}=\Phi \Delta p R / h$ and rearranging, the rupture criterion is

$$
\frac{\Phi \Delta p R \sqrt{\pi d}}{h K_{I c}} \geq \frac{\sqrt{Q}}{H}
$$

where $\Delta p$ is the pressure difference across the shell. The right-hand side of this equation is plotted as a surface in Fig. 4. This surface divides the parameter space into a rupture regime above the surface and non-rupture regime below the surface. 


\section{Experimental setup}

\subsection{Specimens}

Two sets of experiments were performed on aluminum 6061-T6 tubes. In the first set, the notch depth $(0.56 \mathrm{~mm})$, notch width $(0.3 \mathrm{~mm})$, and tube size $(0.89 \mathrm{~mm}$ in wall thickness, $41.28 \mathrm{~mm}$ in outer diameter, $0.914 \mathrm{~m}$ long) were kept constant for studying the fracture behavior by changing only the notch length (from $12.7 \mathrm{~mm}$ to $76.2 \mathrm{~mm}$ ). The surface notch was oriented axially, located in the middle of the tube length, and cut by a CNC machine using a jeweler's slotting saw.

The second set was performed with shorter tubes $(0.610 \mathrm{~m})$ of the same outer diameter $(41.28 \mathrm{~mm})$, various flaw depth, flaw length, and wall thickness. The properties of aluminum 6061-T6 can be found in Table I. The dimensions can be found in Tables II and III.

Since the actual notch geometry (Figs. 2 and 3) was different from the elliptical crack geometry assumed by Newman and Raju (1981), an approximation was used to relate the model crack length, $2 a$, and the 'actual' crack length, $L$, used in machining

$$
2 a=L+2 \sqrt{R_{\text {saw }}^{2}-\left(R_{\text {saw }}-d\right)^{2}},
$$

where $R_{\text {saw }}$ is the radius of the jeweler's slotting saw.

\subsection{Detonation Tube Assembly}

The experimental setup evolved during the course of the experimental study. There were two sets of experiments with two different specimen lengths. Figure 5 shows a schematic of the experimental setup for the first set of experiments with $0.914-\mathrm{m}$ long specimen tubes. The setup consisted of two aluminum tubes connected together by a flange. The tubes were sealed at one end by a Teflon flange containing the spark plug, and the other end by a flange and a Mylar diaphragm. Inside the detonation tube, a spark first created a flame, which then transitioned to a detonation wave after being accelerated through a Shchelkin spiral. The detonation wave propagated into the thin-wall and preflawed specimen tube. The Mylar diaphragm burst each time so that the effects of a reflected shock wave were minimized. Pressure transducers mounted on the detonation tube measured the pressure profile and wave speeds.

For the second set of tests with $0.610-\mathrm{m}$ long tubes, an additional thick-wall extension tube with pressure transducers was connected by a flange to the aft end of the specimen tube. The pressure transducers were used to study the effects of rupture on the detonation wave. Figure 
6 shows a schematic of the experimental setup for the second set of experiments.

\subsection{InSTRUMENTATION}

The velocity and pressure of the detonation wave were measured by PCB piezo-electric pressure transducers. The pressure transducers were mounted $0.40 \mathrm{~m}$ apart in the detonation tube. The extension tube with additional pressure transducers was used only for the second set of experiments with 0.610 -m long tubes.

Micro-Measurements strain gages were bonded to different locations on the external surface of the tubes to measure circumferential strain. The Trig-Tek amplifiers that amplified the signals from the Wheatstone bridges had a bandwidth of $100 \mathrm{kHz}$.

The spark and data acquisition system was triggered by a Stanford Research Systems digital pulse generator. Both the pressure traces and the strain history were digitized with Tektronix oscilloscopes at a rate of $1 \mathrm{MHz}$. The data were transferred into a computer through a LabVIEW program.

\section{Results and discussion}

\subsection{Crack Propagation Behavior as a Function of Initial} FLAW LENGTH

For the first set of experiments, all parameters except one were fixed. The flaw length $L$ was varied and different fracture behaviors were observed. The CJ pressure, $P_{c j}$, and CJ velocity, $U_{c j}$, were nominally $6.1 \mathrm{MPa}$ and $2.4 \mathrm{~km} / \mathrm{s}$, respectively. The mixture was stoichiometric ethylene-oxygen at an initial pressure of 1.8 bar and room temperature. Figure 7 shows a typical pressure signal. The pressure jumps up to a value close to the CJ pressure when the wave front passes by the transducer at $0.05 \mathrm{~ms}$ and then decays at $1 \mathrm{~ms}$ to a plateau value of about $2 \mathrm{MPa}$. After $2 \mathrm{~ms}$, further decay occurs due to the arrival of the expansion wave created by the diffraction of the detonation out of the open end of the tube. A detailed discussion and model of the pressure profile is given in Appendix B of Beltman and Shepherd (2002).

Due to noise, the three-dimensional structure of the detonation wave front, and the finite size of the pressure transducer, the pressure peak recorded by the pressure transducer is not reliable as an average value for computing structural loads. It is generally recognized in the gaseous detonation literature that for loading computations, computed values instead are more dependable. The CJ velocity and pressure of each 
experiment were calculated with the STANJAN program of Reynolds (1986). The computed values depend on the initial thermodynamic conditions, and the initial temperature was taken to be $300 \mathrm{~K}$ in the computations although minor variations in this occurred between tests. A statistical analysis on the variation of $U_{c j}$ showed that for 20 experiments which had identical initial thermodynamic conditions and a STANJAN $U_{c j}$ of $2.40 \mathrm{~km} / \mathrm{s}$, the measured mean was $2.35 \mathrm{~km} / \mathrm{s}$ with a standard deviation of $0.01 \mathrm{~km} / \mathrm{s}$.

Figures 8 to 11 show tubes of different notch lengths after fracture. The detonation wave traveled from left to right. As the wave propagated past the surface notch, the hoop stress opened the notch into a through-wall crack. Two crack fronts then propagated-one in the forward (i.e., same direction as the detonation wave) and one in the backward direction (i.e., in the opposite direction as the detonation wave). We will refer to these two crack fronts simply as the "forward" and "backward" cracks.

Different fracture behavior was observed for the various notch lengths. For the $L=12.7 \mathrm{~mm}$ and $L=25.4 \mathrm{~mm}$ specimens (Fig. 8 and Fig. 9 , respectively), both the forward and backward cracks propagated straight for some distance, then turned, ran helically around the tube, and were arrested. As the notch length increased, the cracks propagated further and severed the tube into two or three parts. Figure 10 displays a fractured $50.8 \mathrm{~mm}$ notch specimen. The backward crack behaved similarly to those of previous specimens, but the forward crack propagated straight for only a short distance and bifurcated. The two branch cracks then ran around the tube and met on the other side, cutting the tube in two. The $L=76.2 \mathrm{~mm}$ notch specimen (Fig. 11) resulted in bifurcation of both the forward and backward cracks, cutting the tube into three pieces. The middle piece was plastically deformed until it was bent inside-out.

\subsubsection{Repeatability of Bifurcated Crack Paths}

Another experiment on an $L=50.8 \mathrm{~mm}$ specimen was conducted to demonstrate repeatability. Figure 12 shows the resemblance of the forward bifurcated crack paths of two $L=50.8 \mathrm{~mm}$ specimens. Both specimens also exhibited similar helical and arrest behavior for the backward crack.

\subsubsection{Sharp Turns for Branching Cracks vs. Smooth Turns for Single Curving Cracks}

While bifurcated cracks tend to turn sharply with a very small turn radius (Fig. 13), single helical cracks tend to turn smoothly with a large turn radius. Cracks that bifurcated traveled straight for relatively short 
distances after leaving the notch tip before turning sharply. Cracks that did not bifurcate traveled straight for longer distances before turning smoothly.

\subsubsection{Bifurcation "Favoring" the Forward Crack}

Figure 14 shows cases for different tube lengths and initial flaw sizes, in which the forward cracks bifurcated and the backward cracks curved but did not branch. In these shots, the CJ pressures and detonation speeds were nominally held constant at $6.1 \mathrm{MPa}$ and $2.4 \mathrm{~km} / \mathrm{s}$, respectively. These cases are interesting because this kind of asymmetry has not been observed the other way. That is, there has not been a single case in which the backward crack bifurcated and the forward crack did not branch. Crack bifurcation "favoring" the forward crack is perhaps due to the asymmetric profile of the traveling detonation load, which caused the forward crack to have a higher stress intensity.

\subsubsection{Critical Crack Length for Bifurcation}

Crack branching occurs because there is a sufficient energy release rate to support additional cracks. Since the energy release rate scales with the crack length, a valid question is whether or not there is a characteristic crack length for branching to occur. The distance $a^{\prime}$ between the forward notch tip and the forward bifurcation point was measured for several shots and the measurements are shown in Tables IV and V. In these shots, the CJ pressure and detonation speeds were nominally held constant at $6.1 \mathrm{MPa}$ and $2.4 \mathrm{~km} / \mathrm{s}$, respectively. A reasonable choice for the characteristic crack length for branching is the sum of the halfnotch length and bifurcation distance, $a+a^{\prime}$, because it is a figure of merit for scaling the forward crack's energy release rate. The 0.914-m long specimens and $0.610-\mathrm{m}$ specimens have to be analyzed separately because they contained different explosive mass and different energy content. The average critical bifurcation crack length was found to be $60 \mathrm{~mm}$ for the $0.914-\mathrm{m}$ long specimens and $79 \mathrm{~mm}$ for the $0.610-\mathrm{m}$ long specimens.

\subsubsection{Crack Length for Non-bifurcating Curved Cracks}

Table VI shows the distance between the notch tip to the arrested crack tip for shots that did not exhibit crack branching. No clear correlation has been found amongst variables such as the stress intensity factor (based on the dynamic hoop stress and initial notch length), detonation pressure, initial notch length, and final crack length. Even for shots with apparently identical conditions $(90,113,114)$, the crack length was not reproducible. It is suspected that uncontrolled variables such as prestress induced by tube misalignment and also dimensional and 
material variation between individual tubes were responsible for the apparent lack of correlation and reproducibility. The tubes were not all from the same lot of material. The outer diameter had an uncertainty of $\pm 0.3 \mathrm{~mm}$, and the wall thickness had an uncertainty of $\pm 0.09 \mathrm{~mm}$.

\subsection{Strain Response}

Just as the fracture behavior was studied by keeping all parameters constant except the notch length, the hoop strains near the notch were examined by keeping everything fixed except the pressure loading. Figure 15 shows the strains for three different specimens with the same tube and notch geometry but different detonation pressures (Shots 30, 31, and 34). As a control experiment, an identical tube with no notch and undergoing only elastic deformation was also tested (Shot 33). Time $t=3 \mathrm{~ms}$ corresponded to the spark used to initiate detonation. Six strain gages were placed near the notch; their locations are shown in Fig. 16. Four of these were aligned with the notch, one was $90^{\circ}$ from the notch, and one was $180^{\circ}$. Figure 17 (d) is a photograph of tube 34 after the experiment (detonation wave direction is from left to right). Figure 18 shows a schematic of the crack propagation direction for Shot 24 and Fig. 19 shows a corresponding photograph, and Figures 17 (c) and (d) show the same for Shot 34 . The strain rates ranged from $10^{2}$ $\mathrm{s}^{-1}$ to $10^{3} \mathrm{~s}^{-1}$.

\subsubsection{Dynamic Hoop Strain Characteristics of a Detonation Tube}

Shot 33 shows typical elastic strains of flexural waves excited by detonation waves that travel above $v_{c 0}$ but below $v_{c 1}$. While the reader is referred to Beltman and Shepherd (2002) for a more detailed discussion, several points are worth mentioning here. First, the strain front coincides with the detonation wave front. Second, the frequencies of the strains correspond closely to the Tang (1965) model's theoretical steady-state frequency, which is $39 \mathrm{kHz}$ for this tube. Third, the measured $\Phi$ here is about 1.5, and thus, our assumed value of 2 for the fracture threshold model is apparently too high. Fourth, since the flexural waves were dispersive and the detonation wave was traveling above $v_{c 0}$, precursor waves at frequencies over $1 \mathrm{MHz}$ would travel ahead of the strain signals seen here. The reasons that they are invisible are that 1) they are of small amplitude compared to the main signal, and 2) the amplifiers, having a bandwidth of $100 \mathrm{kHz}$, attenuated the high-frequency precursors. Fifth, beating can be observed in all of the strain traces due to flexural wave reflections from the tube ends. Sixth, the disparity among individual strain signals is mainly caused by the gages' different, albeit close, axial locations on the tube and 
multiple wave reflections from the tube ends. As it will be shown in the next section, the differences in dynamic strain histories shown here are not primarily caused by tube misalignment or other non-axisymmetric boundary conditions.

4.2.2. Effect on Surface Hoop Strains due to Bulging Near the Notch Comparison between Shots 31 (notched tube with no rupture) and 33 (no notch and no rupture) reveals that the presence of the notch reverses the sign of the hoop strains (gages 2 and 3 ) near the notch. This is expected because as the notch edges bulged under internal pressure, the local curvature of the shell changed and the local strain became compressive. Figure 20 shows an illustration. The compression is not unlike the one experienced by one side of a cantilever beam under distributed load. This effect was not experienced by gages 1, 4, 5, and 6 as they were further away from the notch.

In Shot 30, a higher pressure was used on a notched tube, which ruptured with the crack confined inside the notch. An abrupt change from tensile to compressive strains for gages 1 and 4 and the sudden increase in compression for gages 2 and 3 suggest that crack initiation occurred at about $4.2 \mathrm{~ms}$, or $0.2 \mathrm{~ms}$ after the arrival of the detonation wave front. The change in sign for gages 1 and 4 is due to increased bulging after the loss of material continuity in the notch.

\subsubsection{Hoop Strains for Catastropic Structural Failure}

Shot 34 was an example of catastrophic structural failure in which cracks propagated both in the forward (following the detonation wave) and backward directions. The two cracks propagated in a helical fashion. Because of the emerging detonation products from the crack, some of the gages did not survive long enough to provide meaningful data. Gages 2 and 3 were put into compression, while gages 1 and 4 were in tension for about $0.1 \mathrm{~ms}$ and then abruptly went into compression when the cracks propagated past the gage location, causing the local shell surface to bulge. Note that strain gage 4 reverted from tension to compression slightly earlier than gage 1, suggesting that the forward crack was propagating faster than the backward crack.

Figure 21 shows strain signals for a specimen whose forward crack bifurcated and the backward crack ran helically. The five strain gages are all aligned with the notch (Fig. 16) and were located differently from those of Shots 30, 31, 33, and 34. The forward crack ran straight for a short distance, passing strain gage 1 before branching into two secondary cracks. The gage recorded tension for a brief period, but then transitioned to compression as did gage 1 in Shot 34. Strain gages 2 
thru 4 in Shot 24 behaved similarly to gages 2 and 3 in Shot 34, while gage 5 in Shot 24 behaved similarly to gage 4 in Shot 34 .

In all of the five cases just discussed, the detonation wave travelled at $2.4 \mathrm{~km} / \mathrm{s}$. This means that the detonation wave front took $0.1 \mathrm{~ms}$ to travel from the strain gages to the end of the specimen tube. The pressure traces in the initiator tube give the approximate duration from the detonation wave front's arrival at the pressure transducer to completion of venting of the detonation products (i.e., coming to atmospheric pressure). It was found that for all of the five cases above, this tube venting time was at least $5 \mathrm{~ms}$.

Abrupt strain jumps at later times such as gage 2 at $4.7 \mathrm{~ms}$ for Shot 34 , gage 1 at $5.1 \mathrm{~ms}$, and gage 2 at $4.8 \mathrm{~ms}$ for Shot 24 were probably due to the flaps of tube material (created by fracture) impacting the support structure.

\subsection{Boundary Conditions, Non-Axisymmetry, and Crack Curving Direction}

Figure 22 shows vividly the effect of non-axisymmetry. It shows specimens whose cracks either curved upwards or downwards for a range of pressures and flaw lengths. There are several potential causes of crack curving. One would expect that if the initial stress, detonation loading, and material properties had been perfectly axisymmetric, the cracks should have run straight. However, up to the time of this writing, no such straight detonation-driven cracks were found. What is more interesting is that, disregarding the bifurcation cases, both the forward and backward cracks always curved upwards or downwards, but never one upwards and another downwards. This phenomena of two cracks always curving towards the same direction causes one to suspect that the curving direction is not random. From this point on, we shall use the sign convention of Fig. 23 to denote the curved crack path directions.

Strains were measured again with the specimen tube rotated about the fixture after each measurement to quantify the amount of nonaxisymmetry. The total strain can be broken up into two parts:

$$
\epsilon_{\text {total }}(t)=\epsilon_{\text {static }}+\epsilon_{\text {dynamic }}(t) \text {. }
$$

The static part is caused by prestress due to end conditions, and the dynamic part is the one superimposed by the detonation load. Static experiments measured the static prestrain, and dynamic experiments measured the detonation-induced dynamic strains. 


\subsubsection{Dynamic Axisymmetry}

A series of four experiments were designed to determine whether the dynamic hoop strains produced by the detonation were axisymmetric. Four experiments (Shots 48 to 51), repeating Shot 33 on the same specimen with only variation of initial axial rotation with respect to the fixture, were performed to measure the effects of boundary conditions on the tube. After Shot 48, the tube specimen was rotated 90 degrees axially with respect to the fixture after every shot until Shot 51 . The goal was to see whether or not strain histories would significantly alter if the tube was turned. If they do, there would not be axisymmetry in the dynamic strains. The strain histories of Shots 48 to 51 are shown in Fig. 24 and can be compared to that of Shot 33 (Fig. 15). The strain amplitudes, frequencies, and beats are reproduced nicely.

\subsubsection{Non-axisymmetry due to Unintentional Static Preload}

Next, the initial strains was examined to determine how much static preload was unintentionally imposed onto the specimen. Static strains in the axial direction were measured after the tube was mounted to the fixture. The rationale for examining the axial strains comes from flat-plate fracture literature, where it is well-known that the T-stress, a non-singular stress component acting parallel to the crack, is sometimes responsible for crack curving in a mode-I dominated fracture (Cotterell and Rice, 1980). A strain gage was mounted axially next to SG6 in the middle of the same specimen used for Shot 33 and Shots 48 to 51. As in the dynamic experiments, the tube was rotated 90 degrees axially with respect to the fixture after every measurement. The results are plotted in Fig. 25. It is clear from this plot that there is measurable prestress present. The fixture caused one part of the tube to go into longitudinal compression and the other into longitudinal tension, much like a beam being bent by end moments.

The Bernoulli-Euler beam theory can be used to curve-fit the measured static strains and infer the bending moment imposed on the specimen by the fixture. The following assumptions are used:

$$
\sigma=\frac{M y}{I}=E \epsilon, y=R_{2} \sin \left(\theta-\theta_{0}\right), I=\frac{\pi\left(R_{2}^{4}-R_{1}^{4}\right)}{4},
$$

where $M$ is the bending moment, $y$ is the perpendicular distance of the strain gage to the neutral plane, $\theta_{0}$ is the angle of the neutral plane relative to the initial angle of rotation of the strain gage, $\theta$ is the angle of rotation of the strain gage, $I$ is the moment of inertia of the tube, $R_{1}$ is the inner radius of the tube, and $R_{2}$ is the outer radius of the tube. Figure 26 shows a diagram of this model. Rearranging, 


$$
\epsilon=\frac{4 M R_{2}}{\pi E\left(R_{2}^{4}-R_{1}^{4}\right)} \sin \left(\theta-\theta_{0}\right)
$$

This curve is plotted on Fig. 25 for $M=8 \mathrm{~N}-\mathrm{m}$ and $\theta_{0}=195^{\circ}$. It is known that T-stresses cause instability in crack paths from twodimensional analysis (Cotterell and Rice, 1980). If this analysis can be extrapolated to the present three-dimensional situation so that crack directions are sensitive to these measured tensile stress distributions, this will explain why the curving cracks shown in Fig. 22 either both go up or both go down and not in random directions. When the tube is put into bending by the fixture, either side of the notch becomes locally tensile or compressive, and the cracks propagate into the tension side.

\subsubsection{Effect on Crack Curving Direction due to Intentional Static Preload}

To further justify that the paths of detonation-driven cracks do follow prestress fields, two experiments (Fig. 27) were performed by applying a wedge load $F$ onto the middle of the tube on either side of the notch to create a deliberate initial bending moment. Figures 28 and 29 show the post-test specimens. The cracks curved as expected, to the tension side of the tube.

\subsection{Comparison of Fracture Threshold Model to EXPERIMENTAL DATA}

The second set of experiments used shorter tubes $(0.610 \mathrm{~m})$ and the parameters being varied included flaw depth, flaw length, wall thickness, and pressure. Experiments on Al6061-T6 tubes of this length were performed (see Tables II and III for loading and geometry). The results are plotted on Fig. 4 using the left-hand side of Eq. 16. The right-hand side of Eq. 16 is the theoretical threshold surface, plotted on the same figure for comparison.

Out of 38 experiments performed on preflawed tubes, only three experimental data points (Shots 16, 28, and 32) were on the 'wrong'

side of the threshold surface. The worst case was Shot 32, which had a normalized stress intensity (parameter on the vertical axis) of $37 \%$ away from its predicted region. The agreement between theory and experiment is unexpectedly good for such a simple model. This is partly due to the fact that A16061-T6 is a relatively brittle metal. Experiments have not yet been performed on higher values of $d / h$ because a shallower initial flaw requires higher detonation pressure to rupture. 


\subsection{FractographS}

Light microscope pictures of fracture surfaces of Shot 34 were taken and are shown in Fig. 17. The magnification was 30X with a Leica GZ4 light microscope which was coupled with a Nikon Coolpix 990 digital camera. The natural scale in these photos is the wall thickness of the tube, which is $0.89 \mathrm{~mm}$. In this shot, both the forward and backward cracks first propagated straight for some distance, turned helically, and were arrested. Two types of fracture surface can be distinguished.

The first type is shown in Fig. 17 (a) and (b). These fracture surfaces are along the straight portion of the cracks. They are relatively rough because 1) they were caused by the predominantly mode-I (opening mode) fracture, and 2) the specimen was ductile, being above its transition temperature. Since the wall was thin, the fracture surfaces were, in general, slanted at $45^{\circ}$ to the specimen's surfaces and were composed almost entirely of shear lips. The second type is shown in Fig. 17 (e) and (f). These fracture surfaces are along the curved portion of the cracks. They are relatively smoother. Here, the cracks had already turned helically along the tube, and the fracture was predominantly mode-III (tearing mode) due to the large outward dynamic motion of the flaps. On some fracture surfaces, shallow striations that are almost perpendicular to the crack path can be seen, such as those in Fig. 17 (f).

\subsection{Effect of Propagating Fracture on the Detonation WAVE}

The detonation wave may quench due to the rapid gasdynamic expansion associated with the flow out of the crack opening. If quenching happens in a rupture accident, this may mitigate the hazards of the detonation wave propagating into a piping system filled with combustible reactants. However, no detonation quenching has been observed so far for the three shots $(14,16$, and 29) that involved fracture and pressure measurement at the extension tube. This is because the cracks traveled too slowly to catch up with the sonic plane of the detonation wave. However, the Taylor expansion wave was affected. Two example cases of the pressure history in the extension tube are shown. Figure 30 shows a case (Shot 14) in which the pressure in the Taylor wave region dropped more rapidly due to rupture. As a comparison, Fig. 31 shows a case (Shot 17, no rupture) in which the pressure in the Taylor wave region did not drop as quickly and did not reach atmospheric pressure in the time interval considered. 


\section{Conclusions}

The key results in this study include 1) qualitative behavior of the crack path of a fracturing detonation tube as a function of initial flaw length, 2) quantitative measurements of strain history, 3) fracture threshold, 4) fractographs, 5) relation of detonation wave propagation direction to crack branching, 6) influence of static prestress on crack curving direction, and 7) influence of rupture on the pressure profile of the detonation wave. The present experiments and analyses demonstrate that the fracture mechanics approach is very useful in studying detonation-driven fracture of aluminum tubes.

Examination of fracture surfaces shows that two types of fractures can be distinguished as the cracks progressed along the tube. As the cracks initially propagated straight under the hoop stress, characteristically rough, slanted surfaces were created. After the cracks turned, the large outward dynamic motion of the flaps caused the tearing mode of the fracture to become dominant, and the fracture surfaces to become smoother. Sometimes, shallow striations can be seen. The progression from rough, slanted surfaces to smooth, striated surfaces may help investigators to infer the crack propagation direction in future forensic analysis of detonation-driven pipeline rupture accidents. Fracture mechanics and fractography are widely used in failure investigation and analysis (e.g., see Thielsch, 1965, Engle and Klingele, 1981, Becker and Shipley, 2002), but at present, there are no published data on gaseous detonation driven fracture.

Initial flaw depth has a stronger effect than flaw length on the threshold detonation pressure required to burst a tube. This was demonstrated by the fracture threshold model and experiments. While this is not a precise predictive capability, the fracture threshold model had been an extremely useful engineering tool in the design of our test matrix, correctly identifying trends and enabling the approximate sizing of test specimens and flaw geometry.

The current fracture threshold model, while being able to identify the trend for fracture threshold, needs improvement. A fully dynamic numerical model must be developed in the future to account for bending, shear, inertia, strain rate effects, and plasticity. Moreover, the specimens had blunt notches that are dissimilar from the mathematically sharp crack which the static model assumes. To ensure better agreement between experiment and analysis, one must either initiate a sharp crack (and know how deep it has penetrated) in the tube before each experiment, or develop a numerical method that accounts for the bluntness of the notch. The multi-cycle nature of the stress is obvious from the strain signals. Numerical analysis that attempts to predict 
whether or not the initial crack has propagated through the wall thickness must account for not only the first cycle, but also multiple cycles of stress, and how, during that period, the dynamic stress intensity field evolves as a function of time.

The results of this study should be useful for forensic analysis in pressure vessel and pipeline detonation-driven fracture accidents. Given a portion of postmortem ruptured pipe from an accident, the fact that crack bifurcation favored the forward crack helps to decipher the propagation direction of the detonation wave. Moreover, the fact that initial bending stress causes cracks to curve in one direction helps to give some clues as to the initial stress state of a piping system. Furthermore, experiments have shown cases in which running cracks were unable to quench detonation waves, but the venting caused a quicker drop in loading on the crack flaps.

The fracture behavior can help in deducing the size of the initial flaw if one is present. It was shown that initial flaw length strongly influenced the crack propagation behavior for aluminum tubes under detonation loading. This is expected because larger initial flaws mean higher stress intensity factors and greater crack driving force. Characteristic critical crack lengths for crack bifurcation were also found for different tube lengths. Strain traces measured at strategic positions on the tube were analyzed for different levels of rupture and plastic deformation. The present documentation of postmortem specimens and strain histories should be helpful for researchers who are simulating this type of fluidstructure-fracture interaction.

\section{Acknowledgments}

The authors would like to thank Professor W. G. Knauss and Professor G. Ravichandran for their helpful discussions. This research was sponsored in part through the Office of Naval Research (ONR) contract N00014-99-1-0744 and by the US Department of Energy through the Caltech ASCI project. Their support is gratefully acknowledged. 


\section{Appendix}

Table I. Aluminum 6061-T6 properties

\begin{tabular}{ll}
\hline Property & Value \\
\hline$K_{I c}($ Static $)$ & $30 \mathrm{MPa} \sqrt{\mathrm{m}}$ \\
$\rho$ & $2780 \mathrm{~kg} / \mathrm{m}^{3}$ \\
$E$ & $69 \mathrm{GPa}$ \\
$\nu$ & 0.33 \\
\hline
\end{tabular}




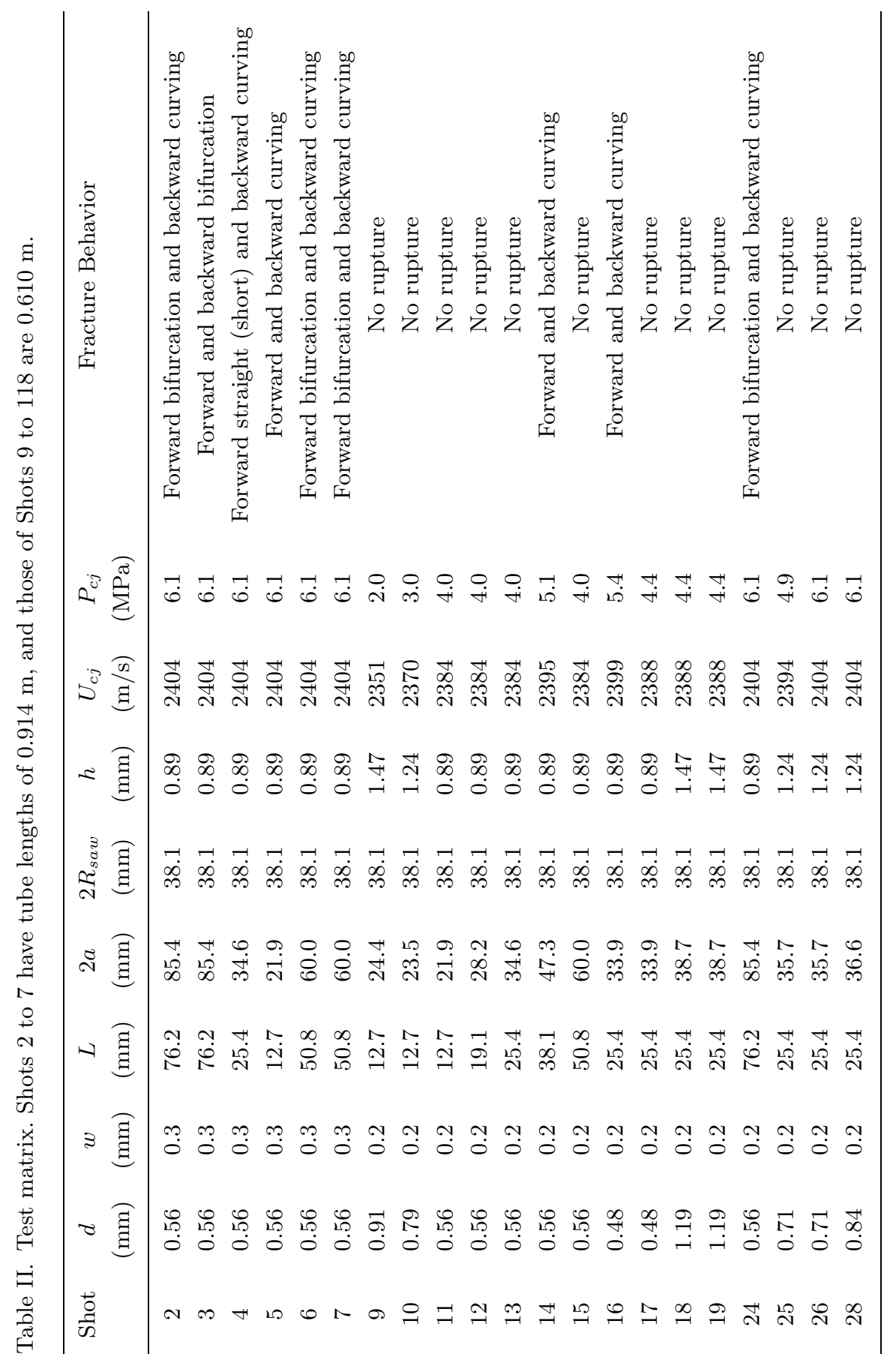




\begin{tabular}{|c|c|}
\hline 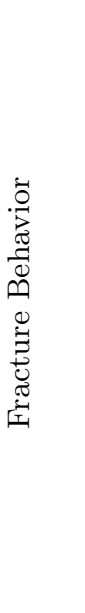 & 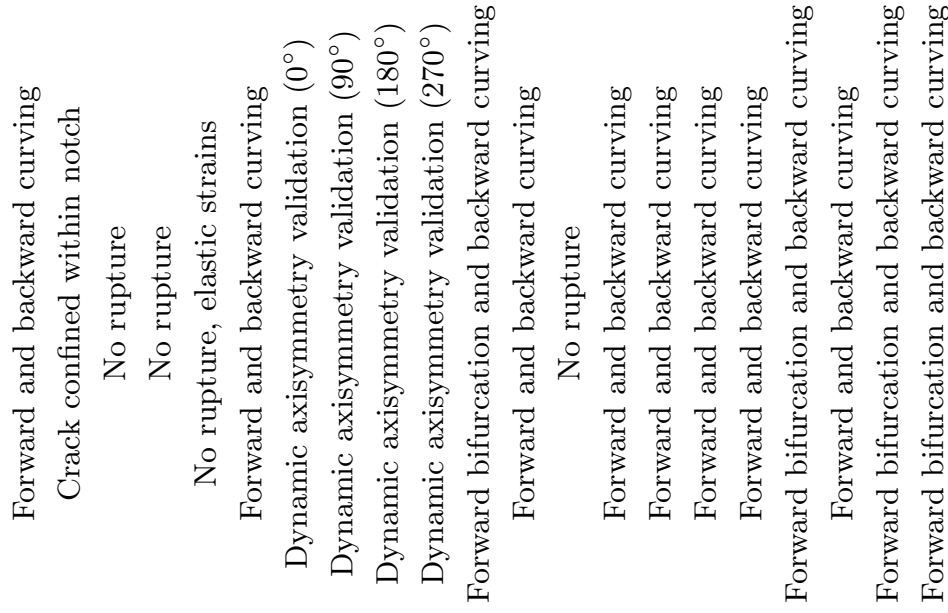 \\
\hline $2^{3} \stackrel{\pi}{a}^{\pi}$ & 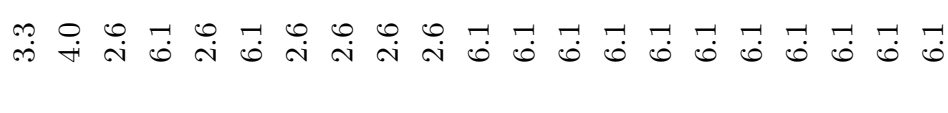 \\
\hline$s \frac{\pi}{g}$ & 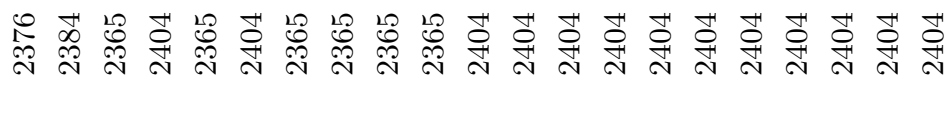 \\
\hline$\simeq$ द्व & 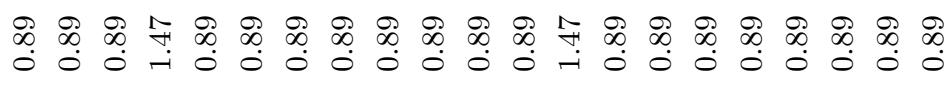 \\
\hline 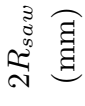 & 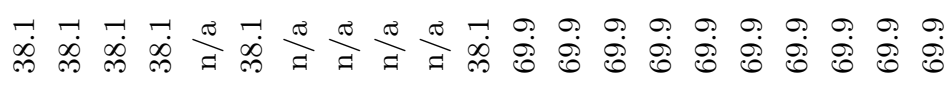 \\
\hline จ $\widehat{g}$ & 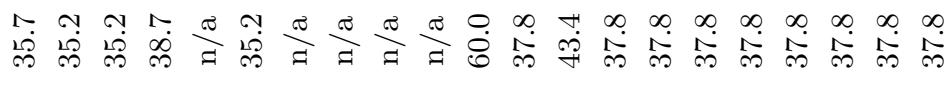 \\
\hline$\leadsto$ द्व్ & 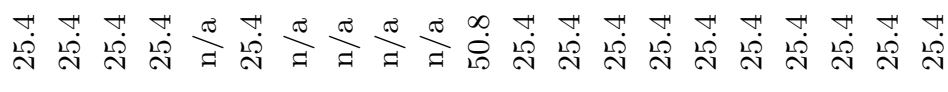 \\
\hline ३ द્व्व & 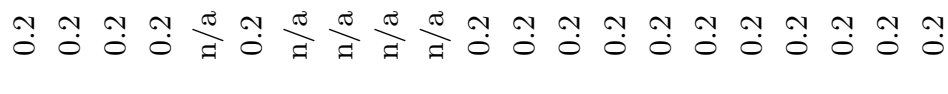 \\
\hline 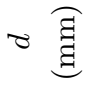 & 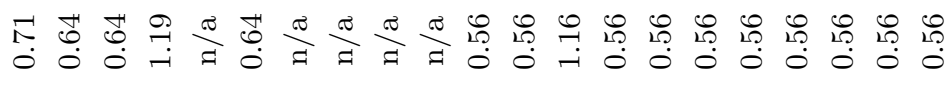 \\
\hline 节 & 虽 \\
\hline
\end{tabular}


T. W. Chao and J. E. Shepherd

Table IV. Critical crack lengths for bifurcation for 0.914-m long tubes.

\begin{tabular}{cccc}
\hline Shot & $2 a(\mathrm{~mm})$ & $a^{\prime}(\mathrm{mm})$ & $a+a^{\prime}(\mathrm{mm})$ \\
\hline 2 & 85 & 24 & 67 \\
3 & 85 & 22 & 65 \\
6 & 60 & 21 & 51 \\
7 & 60 & 29 & 59 \\
Mean & & 60 \\
Average of absolute deviation from mean & 5 \\
\hline
\end{tabular}

Table V. Critical crack lengths for bifurcation for $0.610-\mathrm{m}$ long tubes.

\begin{tabular}{cccc}
\hline Shot & $2 a(\mathrm{~mm})$ & $a^{\prime}(\mathrm{mm})$ & $a+a^{\prime}(\mathrm{mm})$ \\
\hline 24 & 85 & 32 & 75 \\
54 & 60 & 38 & 68 \\
115 & 38 & 64 & 83 \\
116 & 38 & 58 & 77 \\
117 & 38 & 69 & 88 \\
118 & 38 & 63 & 82 \\
Mean & & 79 \\
\multicolumn{2}{l}{ Average of absolute deviation from mean } & 6 \\
\hline
\end{tabular}

Table VI. Length of non-bifurcating curved cracks. All shots listed here have wall thickness $h=0.89 \mathrm{~mm}$.

\begin{tabular}{|c|c|c|c|c|c|c|}
\hline \multirow[b]{2}{*}{ Shot } & \multirow[b]{2}{*}{$\begin{array}{c}d \\
(\mathrm{~mm})\end{array}$} & \multirow[b]{2}{*}{$\begin{array}{c}2 a \\
(\mathrm{~mm})\end{array}$} & \multirow[b]{2}{*}{$\begin{array}{c}l \\
(\mathrm{~m})\end{array}$} & \multirow[b]{2}{*}{$\begin{array}{c}P_{c j} \\
(\mathrm{MPa})\end{array}$} & \multicolumn{2}{|c|}{ Notch tip to crack tip distance } \\
\hline & & & & & $\begin{array}{c}\text { Backward } \\
\quad(\mathrm{cm})\end{array}$ & $\begin{array}{c}\text { Forward } \\
(\mathrm{cm})\end{array}$ \\
\hline 4 & 0.56 & 34.6 & 0.914 & 6.1 & 17.0 & 14.8 \\
\hline 5 & 0.56 & 21.9 & 0.914 & 6.1 & 16.8 & 22.4 \\
\hline 14 & 0.56 & 47.3 & 0.610 & 5.1 & 21.9 & 24.5 \\
\hline 16 & 0.48 & 33.9 & 0.610 & 5.4 & 23.0 & 24.8 \\
\hline 29 & 0.71 & 35.7 & 0.610 & 3.3 & 12.3 & 12.7 \\
\hline 34 & 0.64 & 35.2 & 0.610 & 6.1 & 18.6 & 22.7 \\
\hline 90 & 0.56 & 37.8 & 0.610 & 6.1 & 18.7 & 22.7 \\
\hline 113 & 0.56 & 37.8 & 0.610 & 6.1 & 12.5 & 16.5 \\
\hline 114 & 0.56 & 37.8 & 0.610 & 6.1 & 10.7 & 13.4 \\
\hline
\end{tabular}




\section{List of Figures}

1 Steady-state dynamic amplification factor as a function of traveling load speed according to the Tang (1965) model. Curves for Al6061-T6 tubes $(R=20.64 \mathrm{~mm})$ of three different wall thicknesses presented in this paper are plotted. The $U_{c j}$ in the experiments was $2.4 \mathrm{~km} / \mathrm{s}$, at this speed $\Phi \approx 2$.

2 Flat plate model with mathematically sharp crack assumed by Newman and Raju (1981), above, compared to the tubes' actual surface notch with finite width $w$, below.

3 Flaw geometry.

4 Different perspective views of the fracture threshold. The surface divides the space into theoretical rupture (above) and no rupture regimes (below) according to Eq. 16. Experimental data are presented as filled squares for ruptured tubes and open triangles for intact tubes.

$6 \quad$ Second tube assembly with $0.610-\mathrm{m}$ long specimen and a $0.305 \mathrm{~m}$ extension tube.

7 Typical detonation pressure trace recorded by the piezoelectric pressure transducer in the detonation tube.

10 Ruptured tube with initial $L=50.8 \mathrm{~mm}$ notch (Shot 7). 30

11 Ruptured tube with initial $L=76.2 \mathrm{~mm}$ notch (Shot 3). 31

12 Resemblance of the forward bifurcated crack paths of two $L=50.8 \mathrm{~mm}$ notch specimens. The repeated experiments were run to demonstrate reproducibility (Shot 7 on the left and Shot 6 on the right).

13 Sharp turn from a bifurcated crack. Darkened edge at the lower right indicates location of the initial notch. This branch of the crack travelled from right to left and then upwards.

14 Post-test specimens with forward cracks bifurcating and single backward cracks curving, but never with forward single crack curving and backward crack bifurcating. This shows bifurcation favoring the forward crack. The detonation wave ran from left to right. Numbers denote shot numbers. CJ pressures and detonation speeds were nominally held constant at $6.1 \mathrm{MPa}$ and $2.4 \mathrm{~km} / \mathrm{s}$, respectively. Refer to the test matrix for other shot conditions. 
15 Hoop strain of four specimens with the same wall thickness and tube length but different CJ detonation pressure. The flaw sizes were also the same, except Shot 33 , which had no notch. All strain traces start at zero strain. (a) tube with no notch and no rupture (Shot 33). (b) notched tube with no rupture (Shot 31). (c) notched tube with rupture confined within the notch (Shot 30). (d) notched and ruptured tube with forward and backward helical cracks (Shot 34).

16 Strain gage locations for Shots 30, 31, and 34 (above) and Shot 24 (below). Distance between gages was 15.2 $\mathrm{mm}$ for gages 1 through 4 for Shots 30, 31, and 34 . Distance between gages was $25.4 \mathrm{~mm}$ for Shot 24. The strain gage locations for Shots 33 and 48 to 51 follow that of 30, 31, and 34. Gage length was $0.81 \mathrm{~mm}$ and gage width was $1.52 \mathrm{~mm}$. Drawing is not to scale.

17 Shot 34 fractographs (a, b, e, f), crack path schematic (c), and specimen (d).

18 Schematic of crack paths of Shot 24. Detonation wave ran from left to right. Drawing is not to scale.

19 Shot 24 specimen. Detonation wave ran from left to right. 36

20 Bulging of the regions near the notch and the cracks caused the local shell curvature to change and thus, gave rise to local compressive strains recorded by strain gages. The compression is not unlike the one experienced by one side of a cantilever beam under distributed load.

21 Notched and ruptured tube with forward bifurcated cracks and backward helical cracks (Shot 24).

22 Post-test specimens with both forward and backward cracks directed upwards or both downwards, but never in different directions. This suggests that crack curving direction may not be random. The detonation wave ran from left to right. Numbers denote shot numbers. Positive and negative signs denote crack path directions. Refer to test matrix for shot conditions. See the next figure for crack path sign conventions.

23 Crack path directions following the right-hand screw rule. The fact that the forward and backward cracks did not curve in opposite directions led us to believe that a bending moment $M$ imposed unintentionally by the fixture was a contributing factor for crack curving. Cracks are attracted to the tensile side of the tube under bending. 
24 Dynamic axisymmetry validation: shots with same conditions but with the tube rotated 90 degrees with respect to the fixture after each successive shot. Conditions are same as Shot 33. (a) Shot 48. (b) Shot 49. (c) Shot 50. (d) Shot 51.

25 Static longitudinal axial strains (open squares) measured on a strain gage in the middle of the tube. The tube was rotated 90 degrees with respect to the fixture after each successive measurement. The solid line represents the theoretical strains for a fixture-induced bending moment of $8 \mathrm{~N}-\mathrm{m}$.

26 Bernoulli-Euler beam model used to infer the fixtureinduced bending moment $M$ from measured static longitudinal strains. $y$ is the perpendicular distance from the strain gage to the neutral plane and $\theta-\theta_{0}$ is the angle between the strain gage and the neutral plane.

27 Wedge load setup schematic. The upper diagram shows the configuration and crack path for Shot 109, and the lower diagram shows those for Shot 110 . The crack path directions are consistent with the induced bending moment.

28 Shot 109.

30 Pressure history of transducer 3 for Shot 14 that resulted in rupture. The propagating crack resulted in venting the explosion products and increased the rate of pressure decay over that associated with the Taylor wave in a rigid tube as shown in the next figure and discussed in the Appendix of Beltman and Shepherd (2002). The detonation was not quenched. Time zero corresponds to the spark in this case.

31 Pressure history of transducer 3 for Shot 17 that resulted in no rupture. Unlike the pressure profile in the ruptured case of Shot 14, the pressure here dropped at a lower rate and did not go to atmospheric pressure for the time interval considered. Time zero corresponds to the spark in this case. 


\section{Figures}

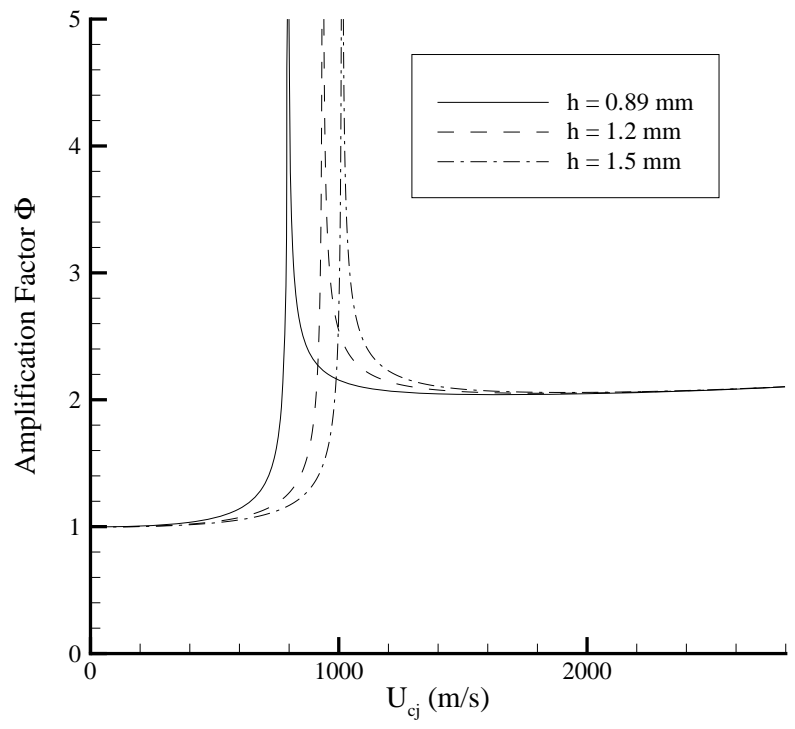

Figure 1. Steady-state dynamic amplification factor as a function of traveling load speed according to the Tang (1965) model. Curves for Al6061-T6 tubes $(R=20.64$ $\mathrm{mm}$ ) of three different wall thicknesses presented in this paper are plotted. The $U_{c j}$ in the experiments was $2.4 \mathrm{~km} / \mathrm{s}$, at this speed $\Phi \approx 2$. 

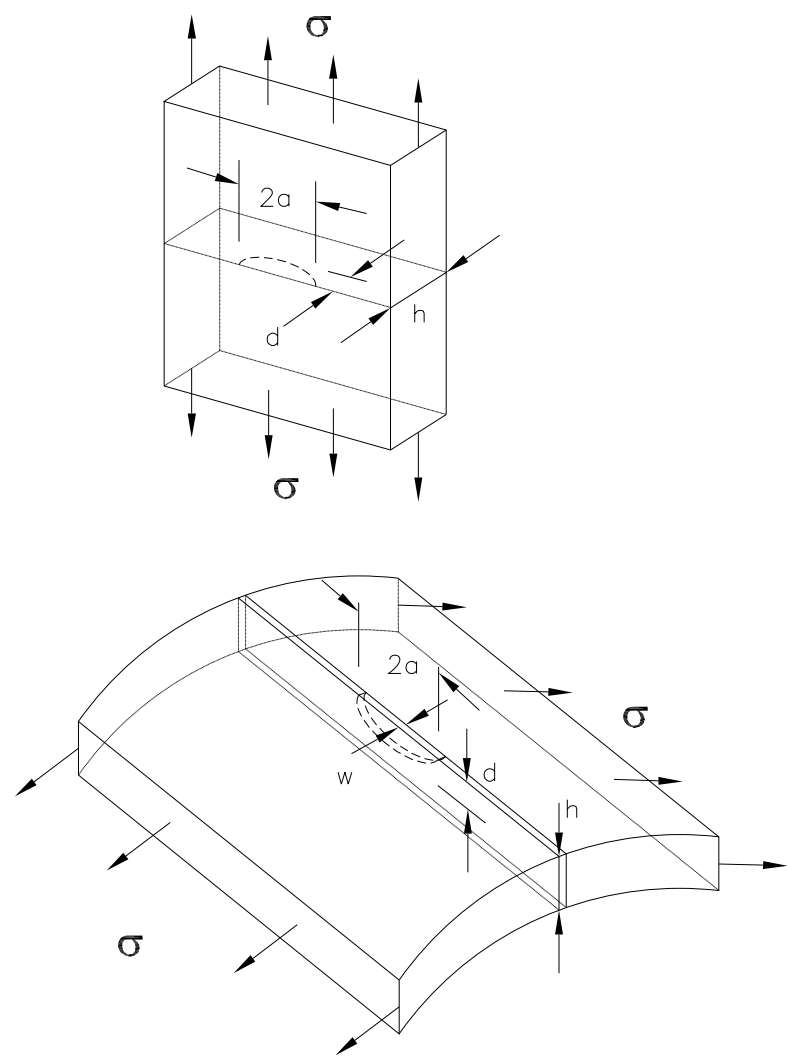

Figure 2. Flat plate model with mathematically sharp crack assumed by Newman and Raju (1981), above, compared to the tubes' actual surface notch with finite width $w$, below.

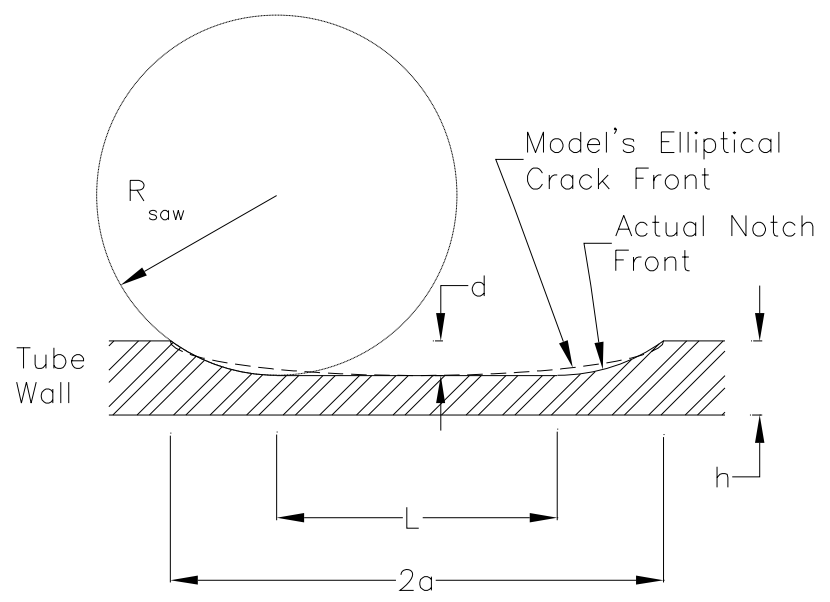

Figure 3. Flaw geometry. 

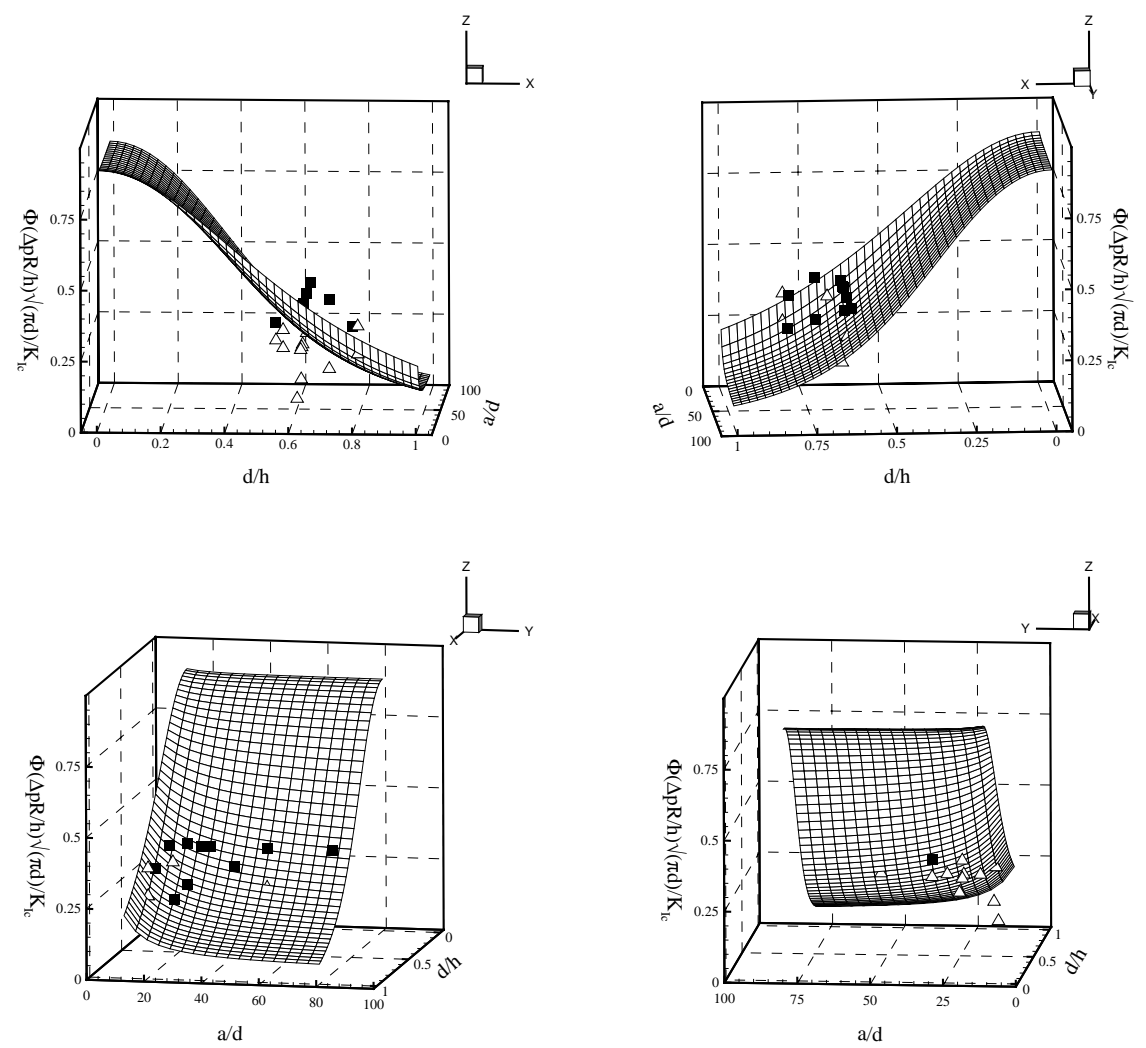

Figure 4. Different perspective views of the fracture threshold. The surface divides the space into theoretical rupture (above) and no rupture regimes (below) according to Eq. 16. Experimental data are presented as filled squares for ruptured tubes and open triangles for intact tubes. 


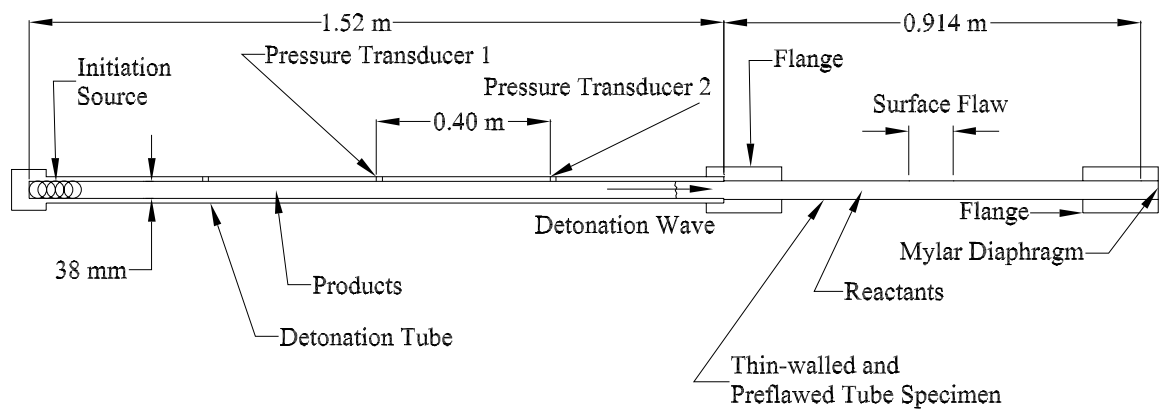

Figure 5. First tube assembly with 0.914-m long specimen.

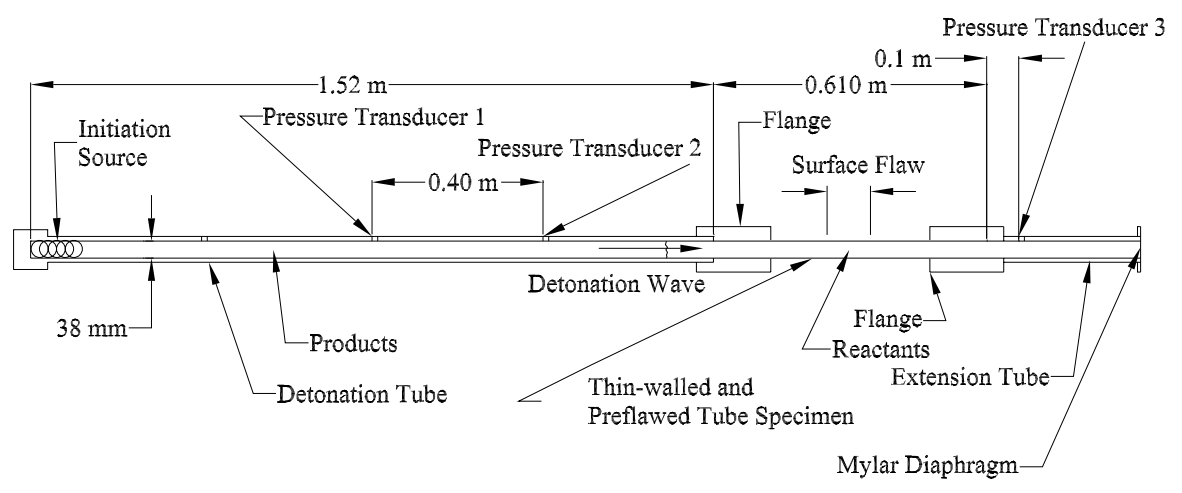

Figure 6. Second tube assembly with $0.610-\mathrm{m}$ long specimen and a $0.305 \mathrm{~m}$ extension tube. 


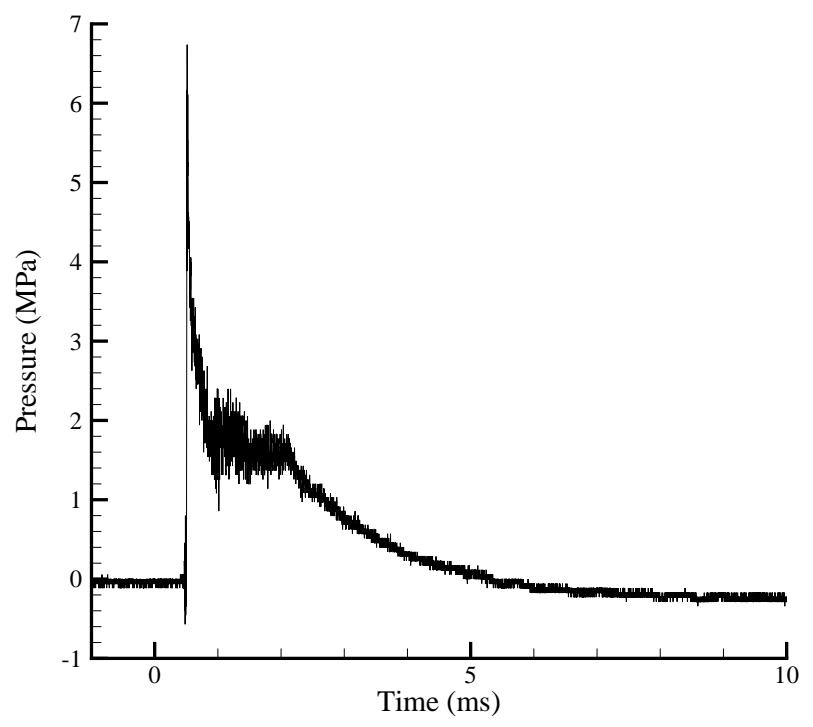

Figure \%. Typical detonation pressure trace recorded by the piezo-electric pressure transducer in the detonation tube.

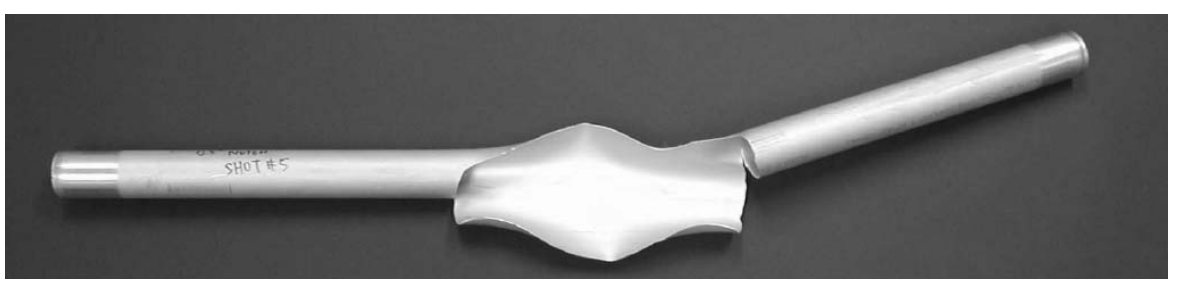

Figure 8. Ruptured tube with initial $L=12.7 \mathrm{~mm}$ notch (Shot 5).

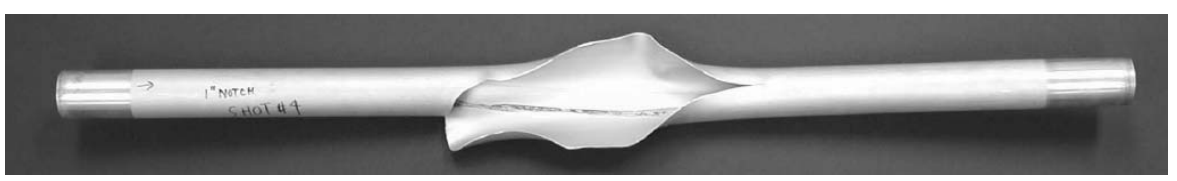

Figure 9. Ruptured tube with initial $L=25.4 \mathrm{~mm}$ notch (Shot 4).

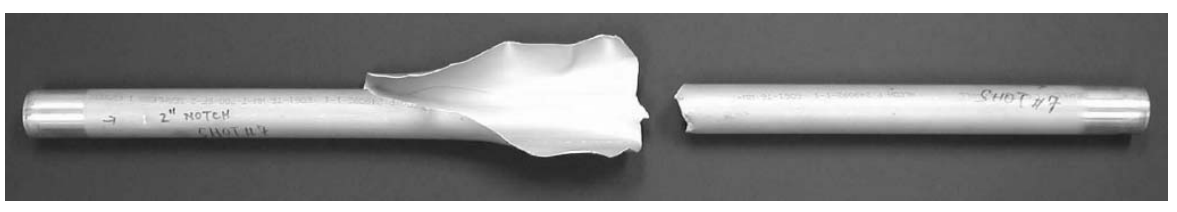

Figure 10. Ruptured tube with initial $L=50.8 \mathrm{~mm}$ notch (Shot 7 ). 


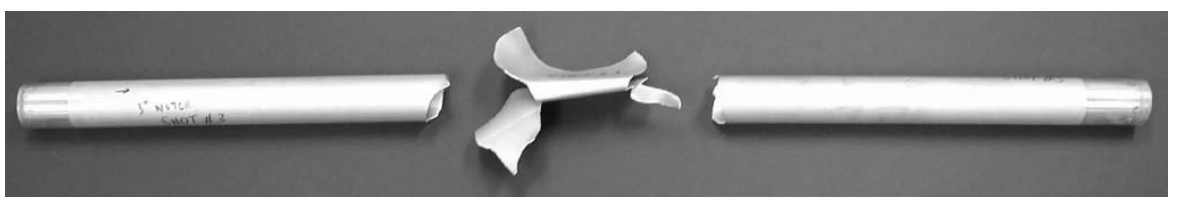

Figure 11. Ruptured tube with initial $L=76.2 \mathrm{~mm}$ notch (Shot 3).

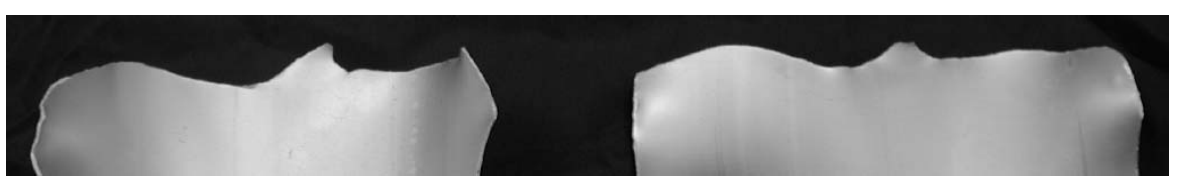

Figure 12. Resemblance of the forward bifurcated crack paths of two $L=50.8 \mathrm{~mm}$ notch specimens. The repeated experiments were run to demonstrate reproducibility (Shot 7 on the left and Shot 6 on the right).

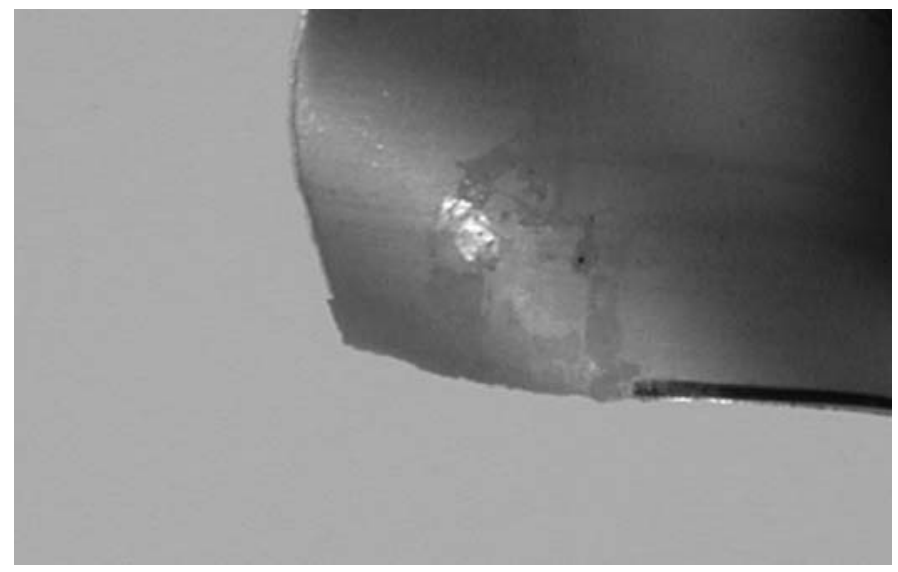

Figure 13. Sharp turn from a bifurcated crack. Darkened edge at the lower right indicates location of the initial notch. This branch of the crack travelled from right to left and then upwards. 


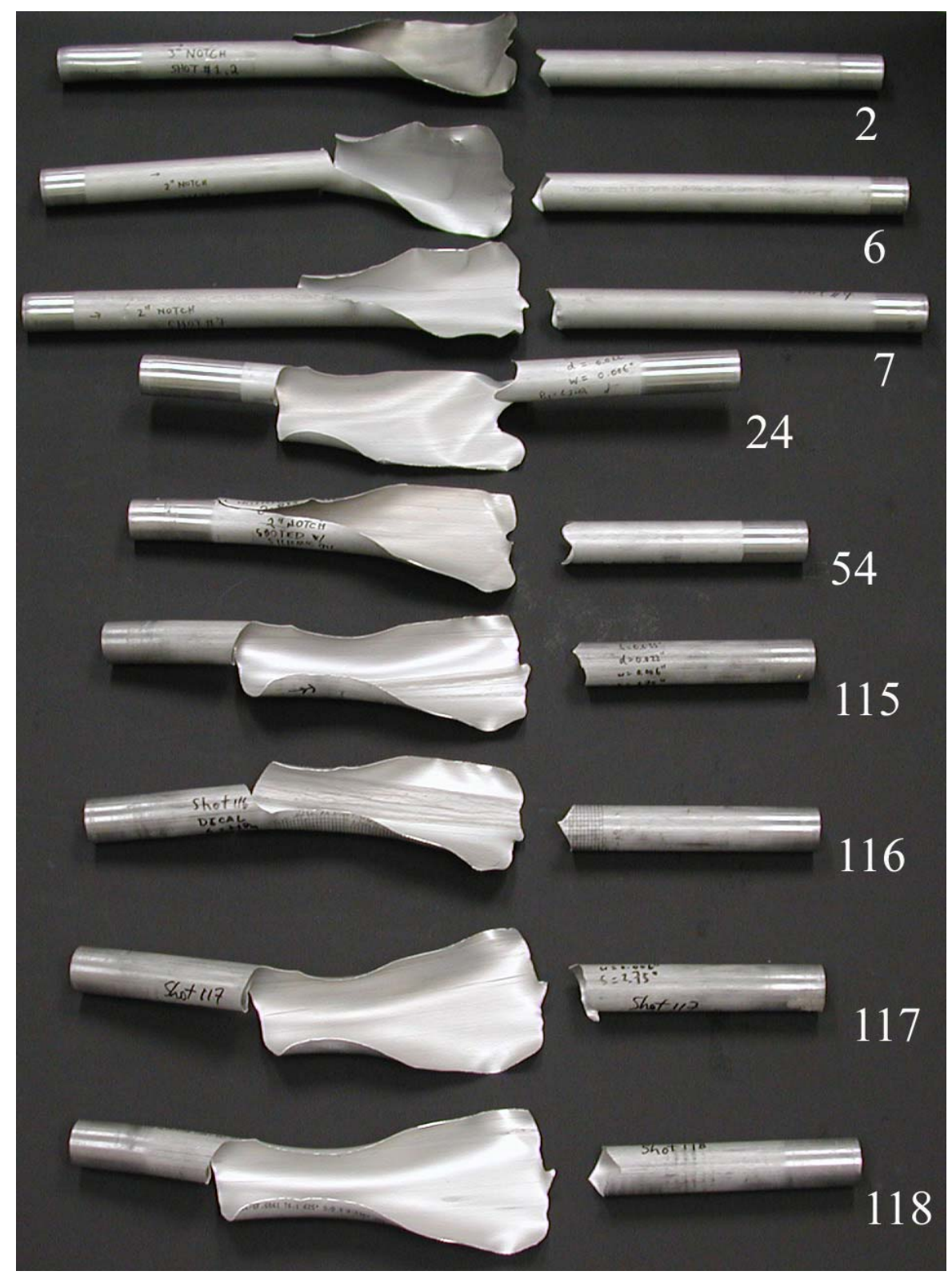

Figure 14. Post-test specimens with forward cracks bifurcating and single backward cracks curving, but never with forward single crack curving and backward crack bifurcating. This shows bifurcation favoring the forward crack. The detonation wave ran from left to right. Numbers denote shot numbers. CJ pressures and detonation speeds were nominally held constant at $6.1 \mathrm{MPa}$ and $2.4 \mathrm{~km} / \mathrm{s}$, respectively. Refer to the test matrix for other shot conditions. 

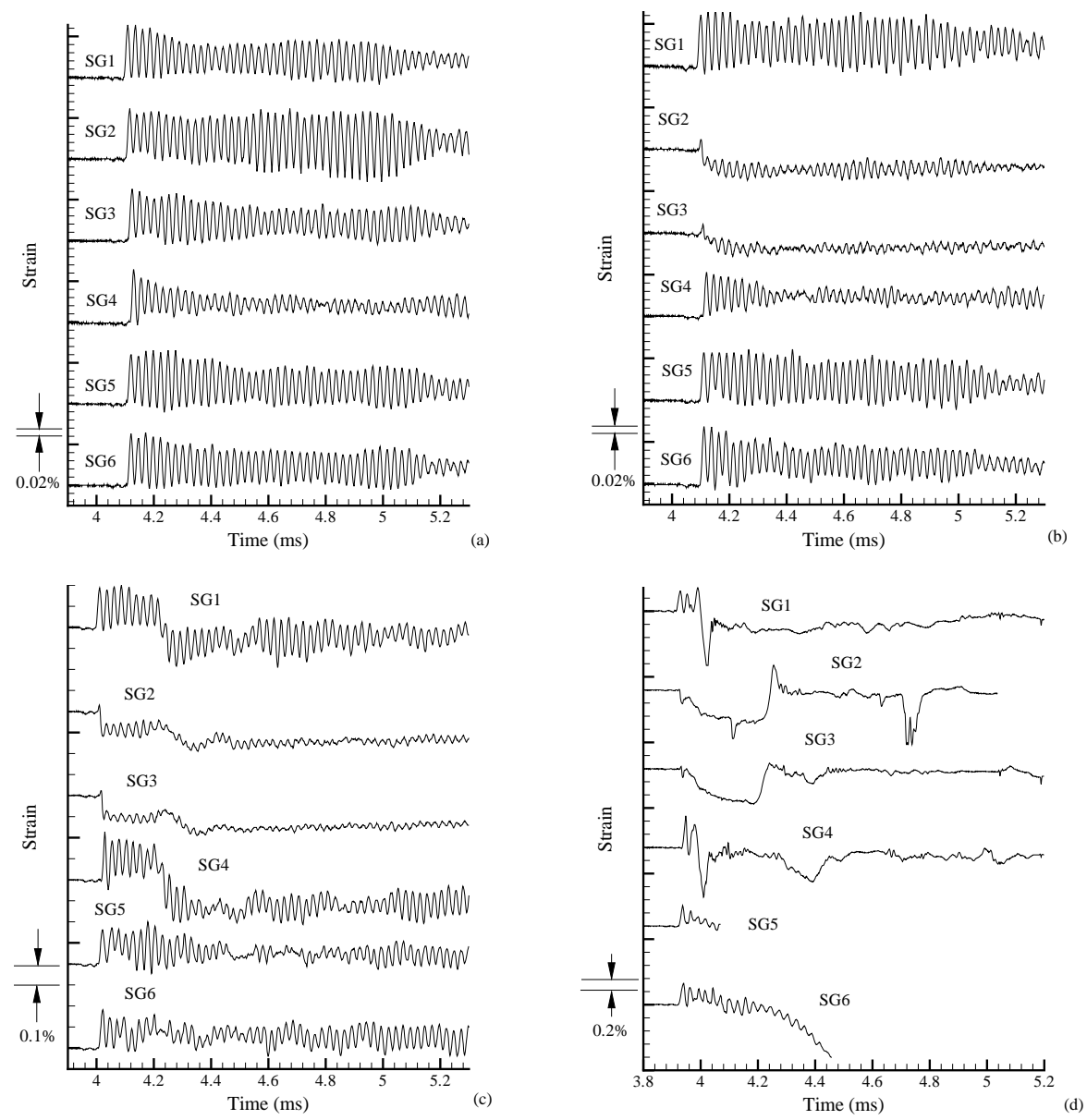

Figure 15. Hoop strain of four specimens with the same wall thickness and tube length but different $\mathrm{CJ}$ detonation pressure. The flaw sizes were also the same, except Shot 33, which had no notch. All strain traces start at zero strain. (a) tube with no notch and no rupture (Shot 33). (b) notched tube with no rupture (Shot 31). (c) notched tube with rupture confined within the notch (Shot 30). (d) notched and ruptured tube with forward and backward helical cracks (Shot 34). 


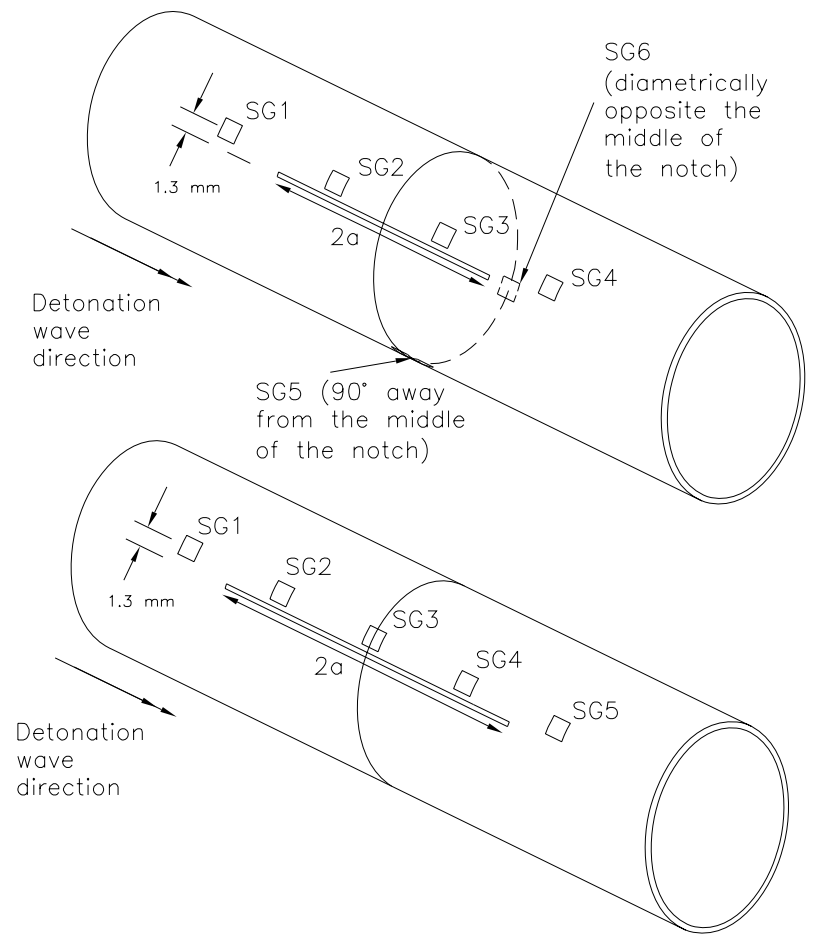

Figure 16. Strain gage locations for Shots 30, 31, and 34 (above) and Shot 24 (below). Distance between gages was $15.2 \mathrm{~mm}$ for gages 1 through 4 for Shots 30, 31, and 34. Distance between gages was $25.4 \mathrm{~mm}$ for Shot 24. The strain gage locations for Shots 33 and 48 to 51 follow that of 30, 31, and 34. Gage length was $0.81 \mathrm{~mm}$ and gage width was $1.52 \mathrm{~mm}$. Drawing is not to scale. 


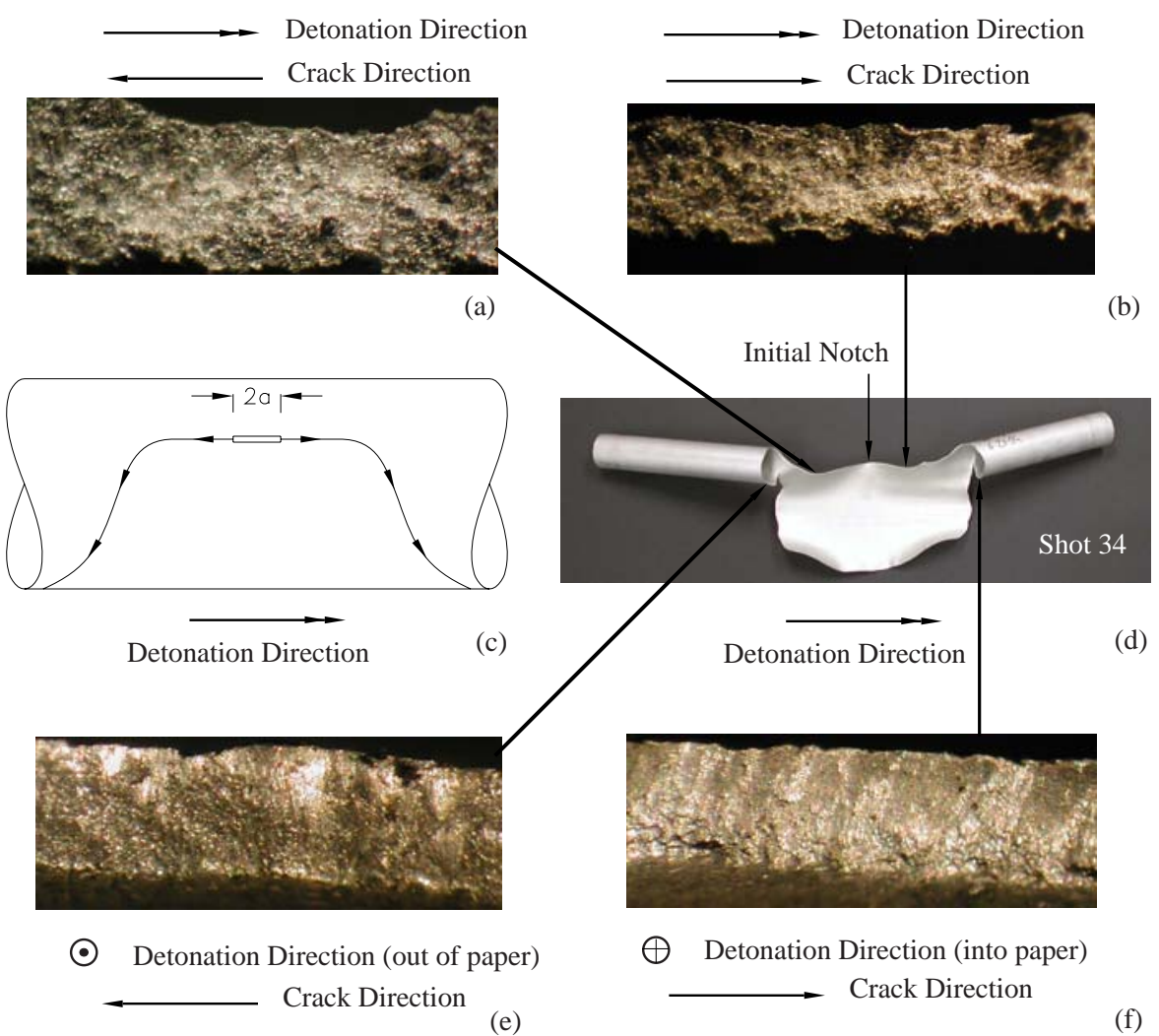

Figure 17. Shot 34 fractographs (a, b, e, f), crack path schematic (c), and specimen (d).

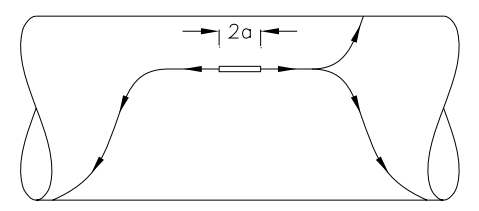

Figure 18. Schematic of crack paths of Shot 24. Detonation wave ran from left to right. Drawing is not to scale. 


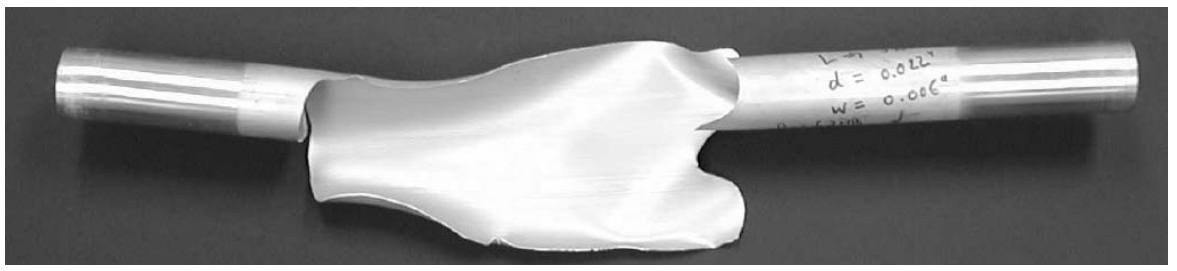

Figure 19. Shot 24 specimen. Detonation wave ran from left to right.

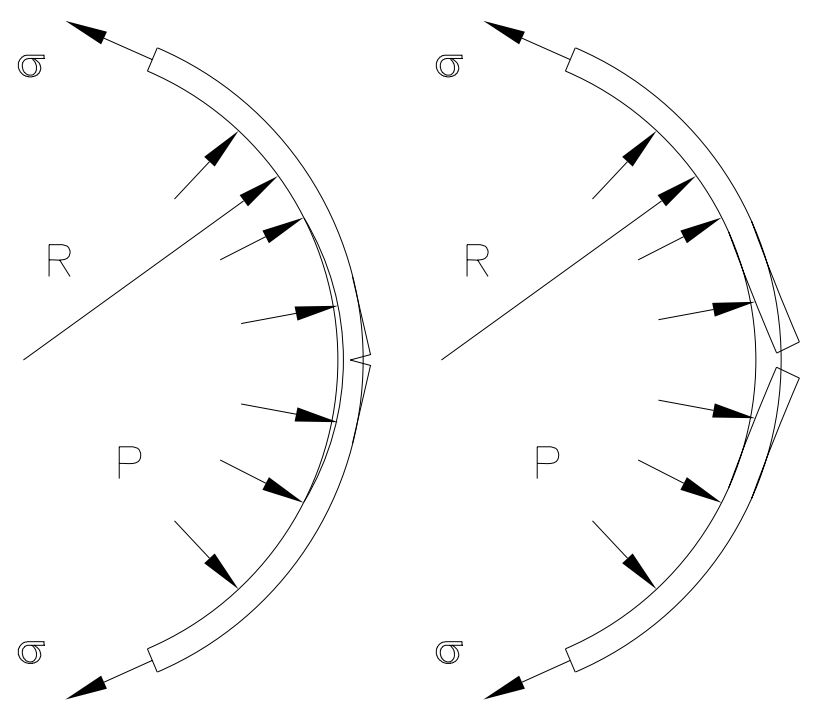

Figure 20. Bulging of the regions near the notch and the cracks caused the local shell curvature to change and thus, gave rise to local compressive strains recorded by strain gages. The compression is not unlike the one experienced by one side of a cantilever beam under distributed load. 


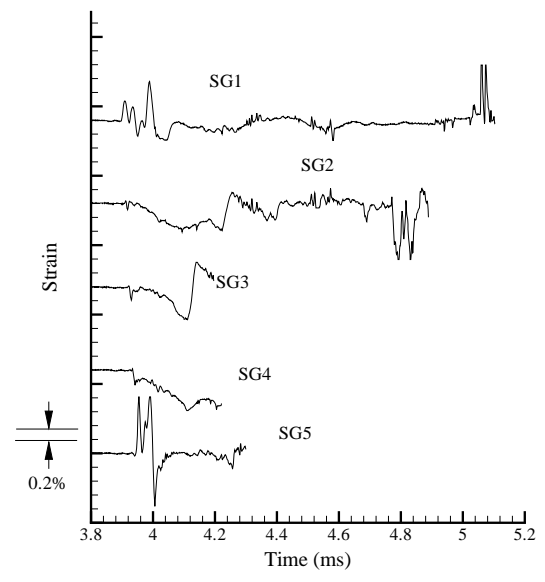

Figure 21. Notched and ruptured tube with forward bifurcated cracks and backward helical cracks (Shot 24). 


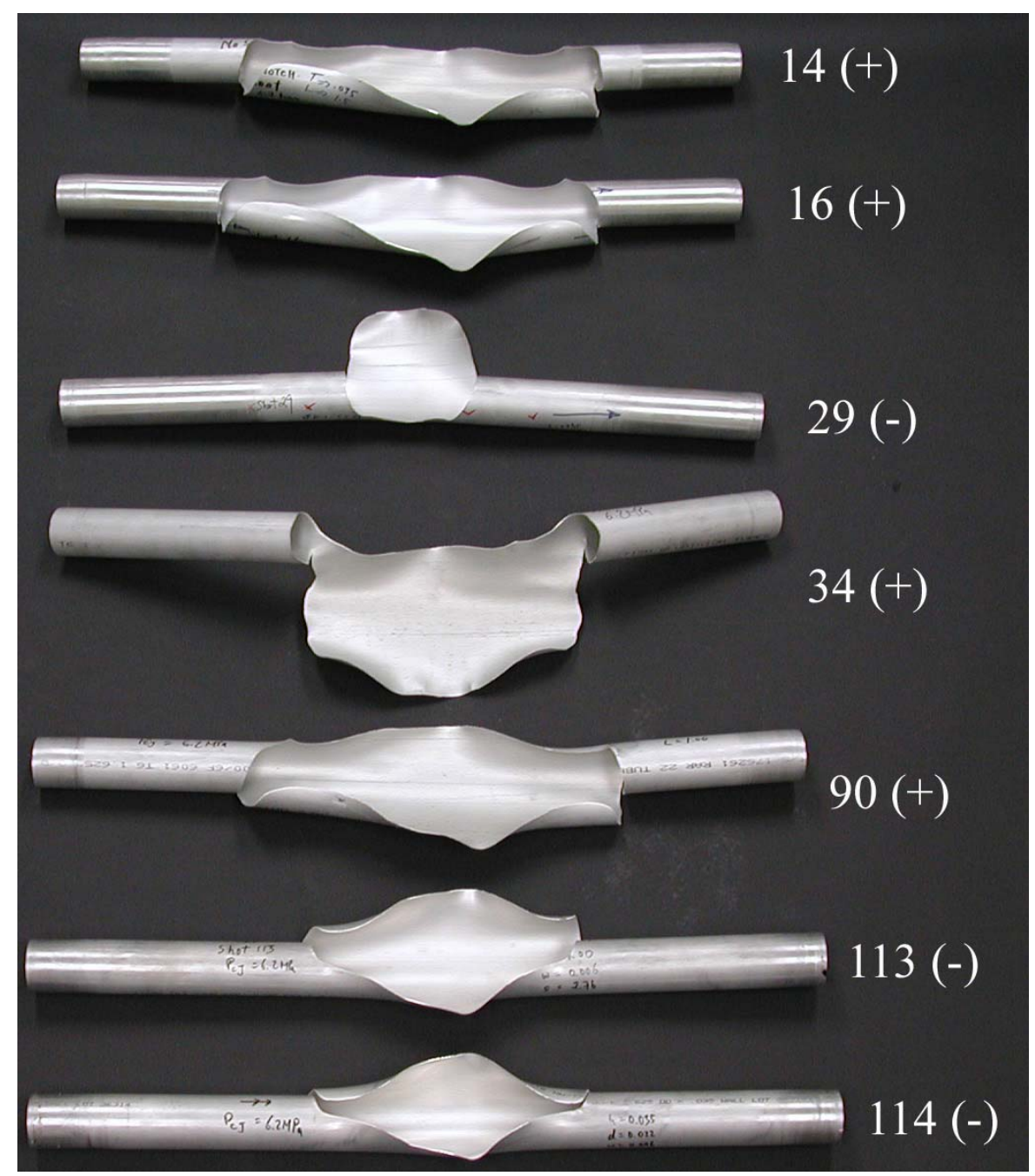

Figure 22. Post-test specimens with both forward and backward cracks directed upwards or both downwards, but never in different directions. This suggests that crack curving direction may not be random. The detonation wave ran from left to right. Numbers denote shot numbers. Positive and negative signs denote crack path directions. Refer to test matrix for shot conditions. See the next figure for crack path sign conventions. 
Negative (-) Crack

Path Direction

$\mathrm{M}$
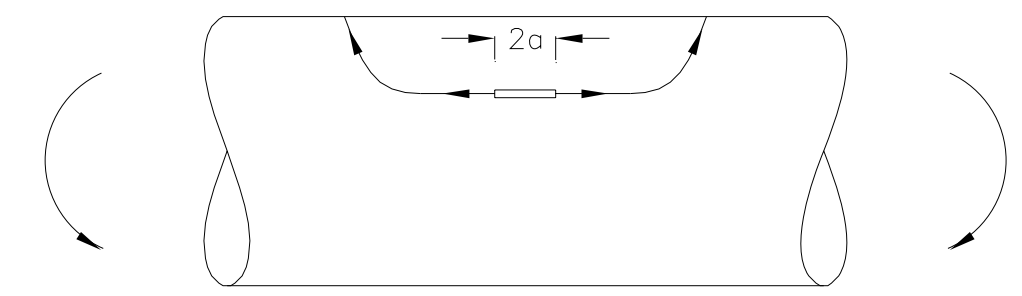

M

Positive (+) Crack

Path Direction

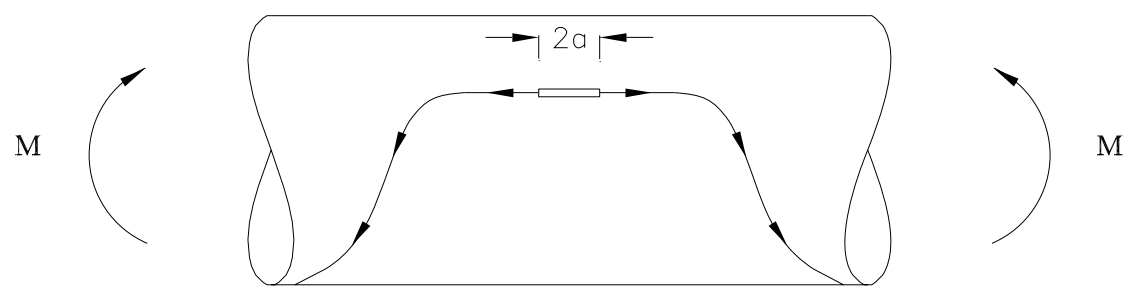

Detonation Wave Direction

Figure 23. Crack path directions following the right-hand screw rule. The fact that the forward and backward cracks did not curve in opposite directions led us to believe that a bending moment $M$ imposed unintentionally by the fixture was a contributing factor for crack curving. Cracks are attracted to the tensile side of the tube under bending. 

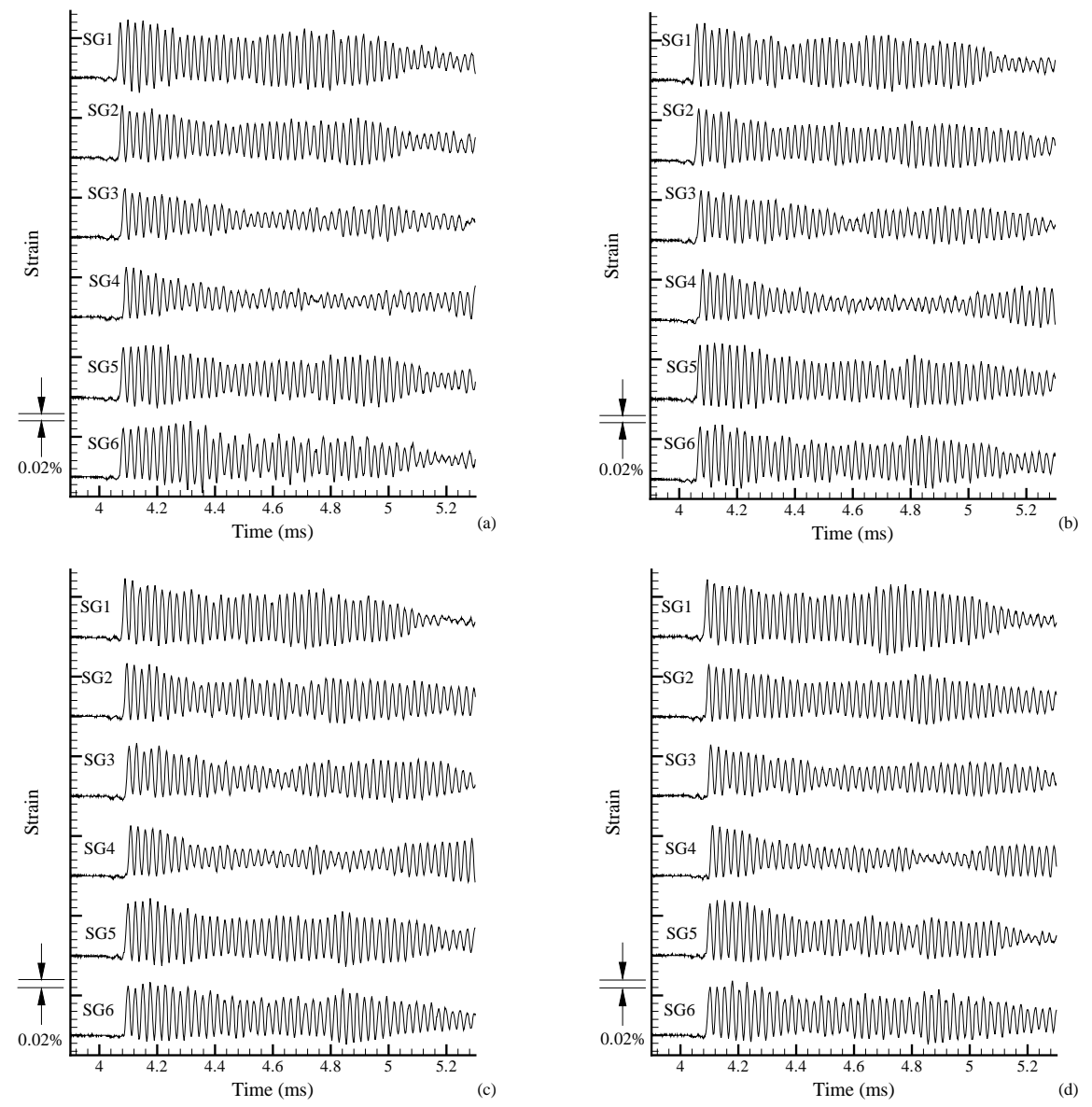

Figure 24. Dynamic axisymmetry validation: shots with same conditions but with the tube rotated 90 degrees with respect to the fixture after each successive shot. Conditions are same as Shot 33. (a) Shot 48. (b) Shot 49. (c) Shot 50. (d) Shot 51. 


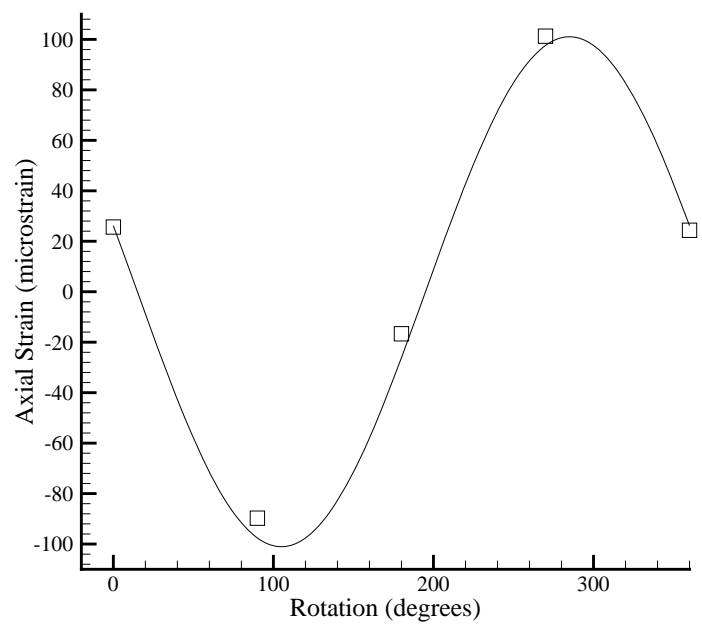

Figure 25. Static longitudinal axial strains (open squares) measured on a strain gage in the middle of the tube. The tube was rotated 90 degrees with respect to the fixture after each successive measurement. The solid line represents the theoretical strains for a fixture-induced bending moment of $8 \mathrm{~N}-\mathrm{m}$.

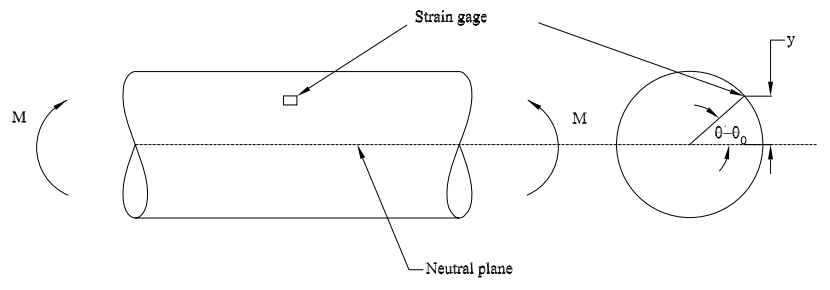

Figure 26. Bernoulli-Euler beam model used to infer the fixture-induced bending moment $M$ from measured static longitudinal strains. $y$ is the perpendicular distance from the strain gage to the neutral plane and $\theta-\theta_{0}$ is the angle between the strain gage and the neutral plane. 

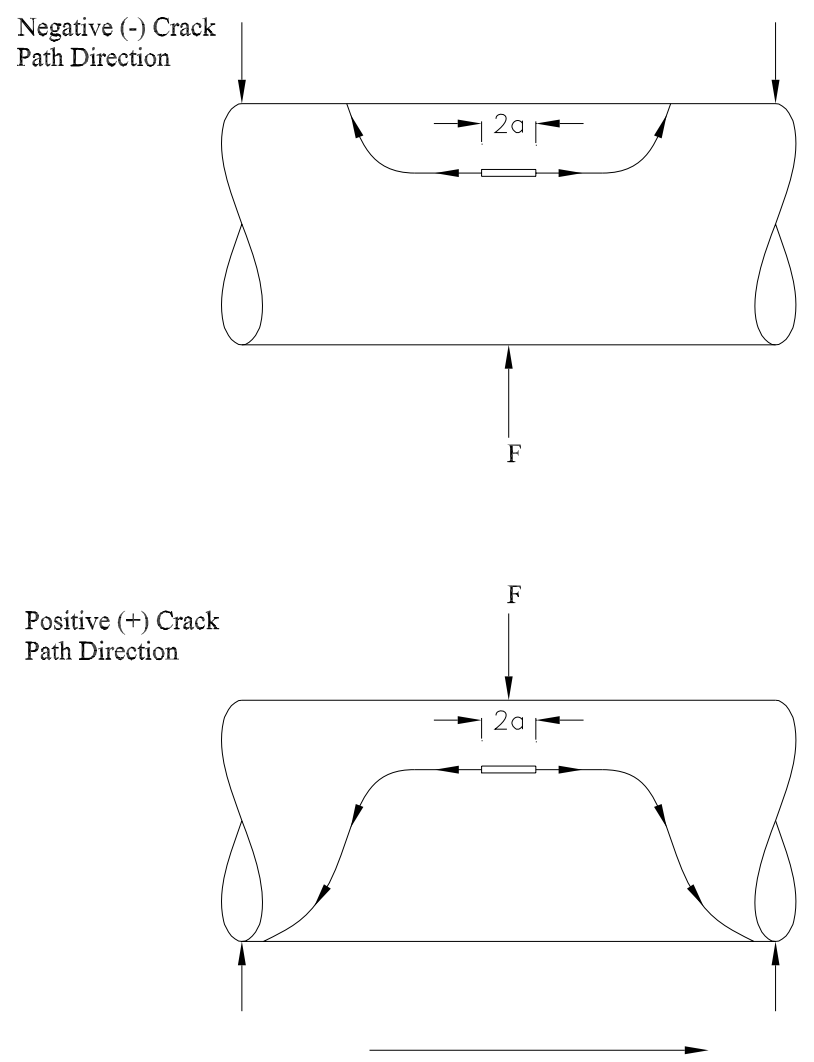

Detonation Wave Direction

Figure 27. Wedge load setup schematic. The upper diagram shows the configuration and crack path for Shot 109, and the lower diagram shows those for Shot 110. The crack path directions are consistent with the induced bending moment. 


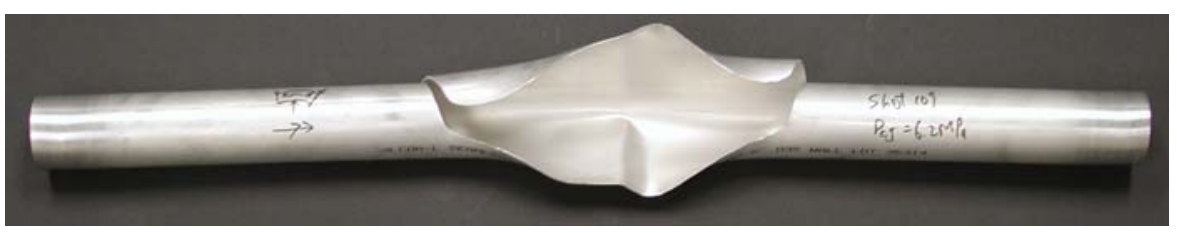

Figure 28. Shot 109.

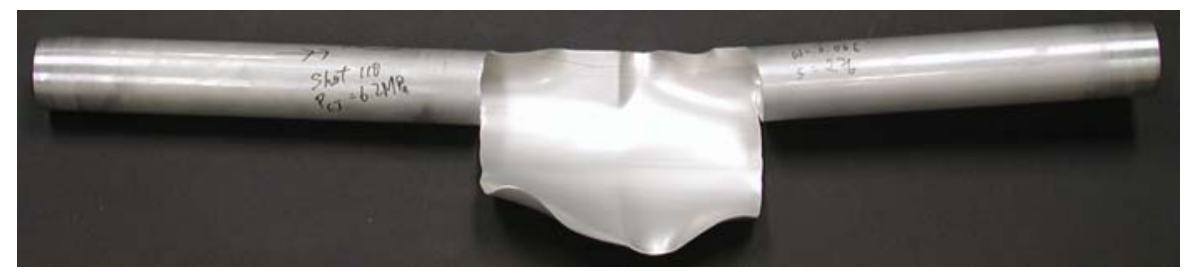

Figure 29. Shot 110 .

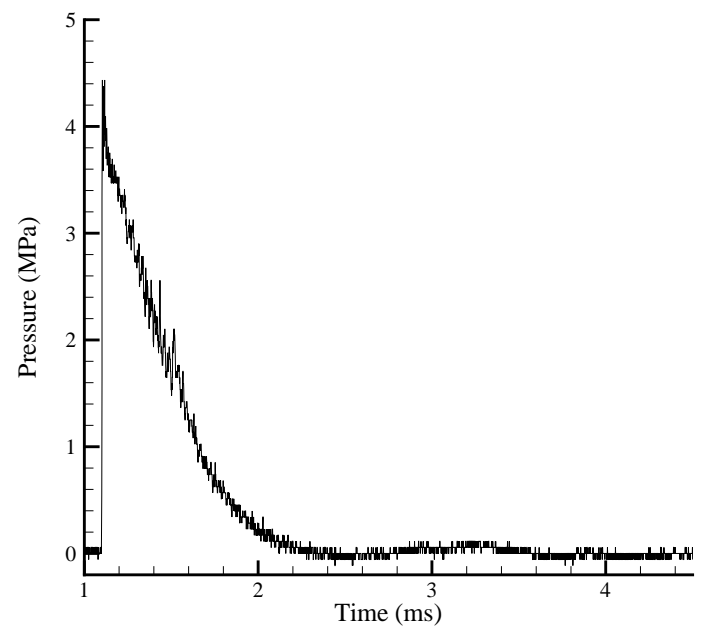

Figure 30. Pressure history of transducer 3 for Shot 14 that resulted in rupture. The propagating crack resulted in venting the explosion products and increased the rate of pressure decay over that associated with the Taylor wave in a rigid tube as shown in the next figure and discussed in the Appendix of Beltman and Shepherd (2002). The detonation was not quenched. Time zero corresponds to the spark in this case. 


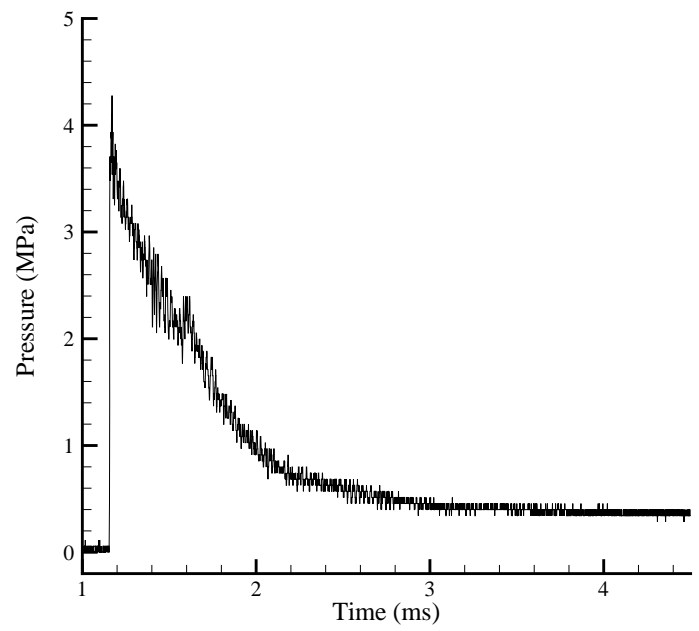

Figure 31. Pressure history of transducer 3 for Shot 17 that resulted in no rupture. Unlike the pressure profile in the ruptured case of Shot 14, the pressure here dropped at a lower rate and did not go to atmospheric pressure for the time interval considered. Time zero corresponds to the spark in this case. 


\section{References}

ASME: 2000, ASME Boiler and Pressure Vessel Code - An International Code. New York, NY: The American Society of Mechanical Engineers. Section VIII, Div. 1 (Part UG-100), Div. 2 (Article T-4).

Becker, W. T. and R. J. Shipley: 2002, ASM Handbook, 10th ed., Vol. 11: Failure Analysis and Prevention. American Society for Metals.

Beltman, W., E. Burcsu, J. Shepherd, and L. Zuhal: 1999, 'The structural response of cylindrical shells to internal shock loading'. Journal of Pressure Vessel Technology 121, 315-322.

Beltman, W. and J. Shepherd: 2002, 'Linear elastic response of tubes to internal detonation loading'. Journal of Sound and Vibration 252(4), 617-655.

Brossard, J. and J. Renard: 1979, 'Mechanical effects of gaseous detonations on a flexible confinement'. In: J. R. Bowen (ed.): Gasdynamics of detonations and explosions: technical papers from the seventh International Colloquium on Gasdynamics of Explosions and Reactive Systems. Göttingen, Federal Republic of Germany, pp. 108-121, AIAA.

Chao, T. W. and J. E. Shepherd: 2004, 'Comparison of fracture response of preflawed tubes under internal static and detonation loading'. Journal of Pressure Vessel Technology 126(3), 345-353.

Cotterell, B. and J. Rice: 1980, 'Slightly curved or kinked cracks'. International Journal of Fracture 16(2), 155-169.

de Malherbe, M., R. Wing, A. Laderman, and A. Oppenheim: 1966, 'Response of a cylindrical shell to internal blast loading'. Journal of Mechanical Engineering Science 8(1), 91-98.

Emery, A. F., A. S. Kobayashi, W. J. Love, B. W. Place, C. Lee, and Y. H. Chao: 1986, 'An Experimental and Analytical Investigation of Axial Crack Propagation in Long Pipes'. Engineering Fracture Mechanics 23(1), 215-226.

Engle, L. and H. Klingele: 1981, An Atlas of Metal Damage. Englewood Cliffs, N.J.: Prentice-Hall.

Fickett, W. and W. C. Davis: 2000, Detonation: Theory and Experiments. Mineola, N.Y.: Dover.

Folias, E. S.: 1965, 'A Finite Crack in a Pressurized Cylindrical Shell'. International Journal of Fracture Mechanics 1, 104-113.

Ives, K., A. Shoemaker, and R. McCartney: 1974, 'Pipe deformation during a running shear fracture in line pipe'. Journal of Engineering Materials and Technology 96(4), 309-317.

Kiefner, J. F., W. A. Maxey, R. J. Eiber, and A. R. Duffy: 1973, 'Failure Stress Levels of Flaws in Pressurized Cylinders'. In: ASTM STP 536, Progress in Flaw Growth and Fracture Toughness Testing, Proceedings of the 1972 National Symposium on Fracture Mechanics.

Kobayashi, A. S., A. F. Emery, W. J. Love, and Y. H. Chao: 1988, 'Subsize Experiments and Numerical Modeling of Axial Rupture of Gas Transmission Lines'. Journal of Pressure Vessel Technology 110, 155-160.

Maxey, W. A., J. F. Kiefner, R. J. Eiber, and A. R. Duffy: 1971, 'Ductile Fracture Initiation, Propagation, and Arrest in Cylindrical Vessels'. In: ASTM STP 514, Fracture Toughness, Proceedings of the 1971 National Symposium on Fracture Mechanics PART II.

Newman, Jr., J. and I. S. Raju: 1981, 'An Empirical Stress-Intensity Factor Equation for the Surface Crack'. Engineering Fracture Mechanics 15(1-2), 185-192. 
Reismann, H.: 1965, 'Response of a pre-stressed cylindrical shell to moving pressure load'. In: S. Ostrach and R. Scanlon (eds.): Eighth Midwest Mechanics Conference. pp. 349-363, Pergamon Press.

Reynolds, W.: 1986, 'The element potential method for chemical equilibrium analysis: implementation in the interactive program STANJAN'. Technical report, Mechanical Engineering Department, Stanford University.

Simkins, T.: 1987, 'Resonance of flexural waves in gun tubes'. Technical Report ARCCB-TR-87008, US Army Armament Research, Development and Engineering Center, Watervliet, N.Y. 12189-4050.

Tang, S.: 1965, 'Dynamic response of a tube under moving pressure'. In: Proceedings of the American Society of Civil Engineers, Vol. 5. pp. 97-122.

Thielsch, K.: 1965, Defects and Failures in Pressure Vessels and Piping. New York: Reinhold.

Thomas, G.: 2002, 'The response of pipes and supports generated by gaseous detonations'. Journal of Pressure Vessel Technology 124, 66-73.

Zhuang, Z. and P. O'Donoghue: 2000, 'Determination of material fracture toughness by a computational/experimental approach for rapid crack propagation in $\mathrm{PE}$ pipe'. International Journal of Fracture 101(3), 251-268. 